\title{
Proteome and functional decline as platelets age in the circulation
}

\author{
Harriet E. Allan ${ }^{1} \odot$ | Melissa A. Hayman ${ }^{1}\left(0\right.$ | Simone Marcone ${ }^{2}$ | Melissa V. Chan ${ }^{1}$ | \\ Matthew L. Edin ${ }^{3}$ | Tania Maffucci ${ }^{4}$ | Abhishek Joshi ${ }^{5}$ | Laura Menke ${ }^{1}$ | \\ Marilena Crescente $^{1}$ | Manuel Mayr ${ }^{5}$ | Darryl C. Zeldin ${ }^{3}$ | Paul C. Armstrong ${ }^{1}$ (0) | \\ Timothy D. Warner ${ }^{1}$
}

${ }^{1}$ Centre for Immunobiology, Blizard Institute, Barts and the London School of Medicine and Dentistry, Queen Mary University of London, London, UK

${ }^{2}$ Department of Surgery, Trinity Translational Medicine Institute, Trinity College Dublin, Dublin, Ireland

${ }^{3}$ National Institutes of Health, National Institute of Environmental Health Sciences, Research Triangle Park, NC, USA

${ }^{4}$ Centre for Cell Biology and Cutaneous Research, Blizard Institute, Barts and the London School of Medicine and Dentistry, Queen Mary University of London, London, UK

${ }^{5}$ King's British Heart Foundation Centre, Kings College London, London, UK

\section{Correspondence}

Timothy D. Warner, Centre for Immunobiology, Blizard Institute, Barts and the London School of Medicine and Dentistry, Queen Mary University of London, 4 Newark Street, E1 2AT London, UK.

Email: t.d.warner@qmul.ac.uk

\section{Funding information}

Funding for this project was provided by Barts \& the London School of Medicine and Dentistry, Queen Mary University of London; the British Heart Foundation (PG/15/47/31591, PG/17/40/33028, RG/19/8/34500); the Division of Intramural Research, National Institute of Environmental Health Sciences, NIH (Z01 ES025034 to D.C.Z.), the Wellcome Trust (101604/Z/13/Z) and the European Union's Horizon 2020 research and innovation programme under the Marie Skłodowska-Curie grant agreement No 675111.

\begin{abstract}
Background: Platelets circulate in the blood of healthy individuals for approximately 7-10 days regulated by finely balanced processes of production and destruction. As platelets are anucleate we reasoned that their protein composition would change as they age and that this change would be linked to alterations in structure and function. Objective: To isolate platelets of different ages from healthy individuals to test the hypothesis that changes in protein content cause alterations in platelet structure and function.

Methods: Platelets were separated according to thiazole orange fluorescence intensity as a surrogate indicator of mRNA content and so a marker of platelet age and then subjected to proteomics, imaging, and functional assays to produce an in-depth analysis of platelet composition and function.

Results: Total protein content was $45 \pm 5 \%$ lower in old platelets compared to young platelets. Predictive proteomic pathway analysis identified associations with 28 biological processes, notably higher hemostasis in young platelets whilst apoptosis and senescence were higher in old platelets. Further studies confirmed platelet ageing was linked to a decrease in cytoskeletal protein and associated capability to spread and adhere, a reduction in mitochondria number, and lower calcium dynamics and granule secretion.
\end{abstract}

Allan, Hayman, Armstrong and Warner contributed equally to this work Manuscript Handled by: Matthew T. Rondina

Final decision: Matthew T. Rondina, 11 August 2021

This is an open access article under the terms of the Creative Commons Attribution License, which permits use, distribution and reproduction in any medium, provided the original work is properly cited.

(c) 2021 The Authors. Journal of Thrombosis and Haemostasis published by Wiley Periodicals LLC on behalf of International Society on Thrombosis and Haemostasis. 
Conclusions: Our findings demonstrate changes in protein content are linked to alterations in function as platelets age. This work delineates physical and functional changes in platelets as they age and serves as a base to examine differences associated with altered mean age of platelet populations in conditions such as immune thrombocytopenia and diabetes.

\section{KEYWORDS}

ageing, blood platelets, cytoskeleton, mitochondria, proteomics

\section{1 | INTRODUCTION}

Platelets circulate for approximately 10 days in healthy individuals, ${ }^{1-3}$ responding rapidly as central players in hemostasis. These dynamic and metabolically active fragments contain a complex array of extracellular proteins, signaling pathways and intracellular machinery including storage granules, canalicular systems, mitochondria, and contractile proteins. Analyses of the platelet proteome have revealed a high degree of similarity in protein content among healthy individuals, with over 3000 proteins detected. ${ }^{4}$ Being cellular fragments, platelets lack a nucleus and have only limited capacity to synthesize new proteins. However, to date studies have largely been conducted on platelets separated as a single cell type from whole blood, and so represent the collective proteome across platelets of all ages.

Newly formed platelets contain an array of the messenger ribonucleic acids (mRNA) which were present in their progenitor megakaryocyte..$^{5-7}$ These residual mRNAs can be used as an indicator of platelet age as they are lost from platelets as they circulate and platelets have limited capacity to generate new mRNA. ${ }^{8-12}$ Numerous studies have reported that newly formed platelets, i.e. those with the highest levels of mRNA, also known as reticulated platelets or the 'immature platelet fraction', are hyper-reactive with an increased thrombotic potential. ${ }^{13-18}$ This hyper-reactivity has been linked to a number of pathological states, including diabetes mellitus and chronic kidney disease, in which there is both increased platelet turnover and higher incidence of acute coronary syndromes associated with reduced effectiveness of standard anti-platelet therapies. ${ }^{19-23}$

A hypothetical explanation for the age-related difference in reactivity is that younger platelets have a greater array of functional pathways to bring to bear to hemostatic processes; they have the full complement of proteins derived from the progenitor megakaryocytes, while these have become degraded or lost in older platelets without the general possibility for replacement. To test this idea, we developed and validated protocols to separate platelets according to circulatory age and carried out proteomic, immunofluorescence and functional assays to delineate physical and functional changes in platelets as they normally age within the circulation.

\section{Essentials}

- Platelets exist within the circulation of healthy individuals for approximately 10 days, during which time there may be functional changes

- Systematic categorization of alterations in the proteome and associated changes in function across platelet lifespan are lacking

- Platelet ageing is marked by a decline in protein content, particularly proteins associated with dynamic processes and associated reductions in hemostatic function

- Our work highlights important changes in the platelet proteome and associated reductions in hemostatic function as platelets age within the circulation

\section{2 | MATERIALS AND METHODS}

\subsection{Ethical statement: murine studies}

Animal procedures were conducted under UK Home Office project license authority (PPL/8422) in accordance with "The Animals (Scientific Procedures) Act 1986", EU directive 2010/63/EU, and were subject to local approval from Queen Mary University of London and Imperial College London Ethical Review Panel.

\subsection{In vivo labelling and flow cytometric sorting of murine young and old platelets}

Male C57BI/6 wild-type mice (8-12 weeks) were purchased from Charles River UK. Anti-CD42c DyLight-x488 or x649 (Emfret) were administered (intravenous) as per supplier guidance. Briefly, antiCD42c-x488 was injected at 0 h, followed by anti-CD42c-x649 23 h later. Blood was collected and platelet rich plasma (PRP) isolated as previously published. ${ }^{24}$

Murine platelets were sorted using BD FACS Aria Illu Fusion Cell Sorter (70 $\mu \mathrm{m}$ nozzle, 70 Ps; BD Bioscience); old platelets were 
gated as CD42c-x488/CD42c-x649 dual positive, and young platelets as CD42c-x649 positive/-x488 negative events. Subsequently, platelets were pelleted at $1000 \mathrm{~g}$ for $10 \mathrm{~min}$ in the presence of prostacyclin $\left(\mathrm{PGI}_{2}, 2 \mu \mathrm{mol} / \mathrm{L}\right.$; Tocris) and re-suspended in Qiazol (QIAGen).

\section{3 | Ethical statement: human studies}

All studies were conducted according to the principles of the Declaration of Helsinki and approved by St Thomas's Hospital Research Ethics Committee (Ref. 07/Q0702/24). All volunteers were screened prior to entering the study and gave written informed consent.

\subsection{Blood collection and isolation of platelets}

Blood was collected by venipuncture into tri-sodium citrate $(3.2 \%$; Sigma) from healthy volunteers (aged 25-40, 60\% female), and platelet rich plasma (PRP) obtained as previously published. ${ }^{22}$

\section{5 | Thiazole orange staining and flow cytometric sorting of platelet subpopulations}

Thiazole orange (TO; $200 \mathrm{ng} / \mathrm{ml}$, Sigma) was incubated with PRP for $30 \mathrm{~min}$ before dilution 1:8 in (i) saline with apyrase $(0.04 \mathrm{U} / \mathrm{ml}$, Sigma), prostaglandin $\mathrm{E}_{1}\left(\mathrm{PGE}_{1}, 2 \mu \mathrm{mol} / \mathrm{L}\right.$, Sigma) and phosphodiesterase inhibitor 3-isobutyl-1-methylxanthine (IBMX, 0.5 mM; Sigma) for quantitative real time polymerase chain reaction (qRT-PCR) experiments or (ii) modified Tyrode's N-2-hydroxyethylpiperazine-N'-2ethanesulfonic acid (HEPES) buffer (134 mmol/L NaCl, $2.9 \mathrm{mM} \mathrm{KCl}$, $0.34 \mathrm{mmol} / \mathrm{L} \mathrm{Na}_{2} \mathrm{HPO}_{4}, 12 \mathrm{mmol} / \mathrm{L} \mathrm{NaHCO}_{3}, 20 \mathrm{mmol} / \mathrm{L} \mathrm{HEPES}$ and $1 \mathrm{mmol} / \mathrm{L} \mathrm{MgCl}_{2} ; \mathrm{pH}$ 7.4; Sigma), with glucose (0.1\% (w/v); Sigma), apyrase $(0.02 \mathrm{U} / \mathrm{ml})$ and $\mathrm{PGE}_{1}(2 \mu \mathrm{mol} / \mathrm{L})$.

Platelets were sorted using a BD FACS Aria Illu Fusion Cell Sorter (70 $\mu \mathrm{m}$ nozzle, $70 \mathrm{Ps}$; BD Bioscience) gated according to TO fluorescence intensity (Figure S1). The platelets were pelleted at $1000 \mathrm{~g}$ for $10 \mathrm{~min}$ in the presence of $\mathrm{PGI}_{2},(2 \mu \mathrm{mol} / \mathrm{L}$; Tocris $)$ and re-suspended in modified Tyrode's HEPES (MTH) buffer, supplemented with calcium chloride $\left(\mathrm{CaCl}_{2}, 2 \mathrm{mmol} / \mathrm{L}\right.$; Sigma).

\subsection{Flow cytometric measurement of activation markers pre- and post-sorting}

Pre- or post-sorted platelets were diluted in annexin binding buffer (1:1), incubated with phosphate buffered saline (PBS), thrombin receptor activator peptide-6 (TRAP-6; $30 \mu \mathrm{M}$ ) or adenosine diphosphate (ADP; $30 \mu \mathrm{M}$ ) along with CD42b-BV421 (1:60, Biolegend), PAC-1 FITC (1:12, BD Bioscience) and annexin V APC (1:60, Biolegend) for $30 \mathrm{~min}$. Samples were analyzed on the ACEA
Novocyte 3000 (ACEA Biosciences Inc.) and analysis was performed using NoVo Express 1.3.0 (ACEA Biosciences Inc.)

\subsection{RNA extraction, cDNA synthesis and quantitative real time polymerase chain reaction (qRT-PCR) of sorted platelets}

RNA was extracted from sorted murine (2.5 million per population) or human (10 million per population) platelets using the miRNAEasy mini kit (QIAGen), following manufacturer's instructions. cDNA was synthesized from the extracted platelet RNA using VILO SuperScript for RT-PCR (Life Technologies). Target genes were rationally selected as candidates based on their specificity to platelets. TaqMan FAM-labelled probes (Fisher Scientific); Integrin alpha-IIb (ITGA2B; Mm00439741_m1 and Hs01116228_m1), platelet factor 4 (PF4; Mm00451315_g1 and Hs00427220_g1), tubulin beta-1 chain (TUBB1; Mm01239914_g1 and Hs00258236_m1). qPCR was performed on a ViiA 7 RealTime PCR System (Applied Biosystems) or Applied Biosystems ABI 7900HT instrument (Life Technologies). Data was analyzed using ViiA 7 Software (Applied Biosystems) or SDS software (Life Technologies), respectively.

\subsection{Protein extraction and proteomic analysis of sorted human platelets}

Protein was extracted from sorted platelets ( 65 million per subpopulation) using lysis buffer (100 mM TRIS pH 7.5, 2\% sodium dodecyl sulfate (SDS), 1 cOmplete ${ }^{\text {TM }}$ Mini Protease Inhibitor Cocktail Tablet per $10 \mathrm{ml}$; all Sigma) and protein content determined by Nanodrop Spectrophotometer ND-1000 (Thermo Fisher Scientific).

Proteomic analysis was performed on $30 \mu \mathrm{g}$ of total protein in each subpopulation with tryptic digests obtained using the Filter Aided Sample Preparation protocol using 30k filter units (Microcon YM-30, Millipore) and sequencing grade trypsin (Trypsin Gold, Promega) with an enzyme to protein ratio of 1:50. ${ }^{25}$ The concentration of tryptic peptides was estimated by UV spectrometer at $280 \mathrm{~nm}$, and $10 \mu \mathrm{g}$ peptides were used for mass spectrometry analysis. Sample preparation, LC-MS/MS analysis and data acquisition was performed as previously described. ${ }^{26}$

Raw mass spectrometry data files were processed in the MaxQuant software (v.1.3.0.547). MS/MS spectra were searched using the built-in search engine Andromeda against a human FASTA Uniprot database (release 2016_3). Downstream analysis of proteomic data was performed with MaxQuant using Andromeda software (version 1.3.0.547) and Perseus software (version 1.6.0.7). ${ }^{27}$ Only proteins present in at least $50 \%$ of the samples in at least one group of differently aged platelets were considered identified. The false discovery rate (FDR), determined by reverse database searching, was set to 0.01 for the peptides and proteins. Proteins found to be differentially expressed between groups 
$(p<.05)$ were subjected to pathway mapping analysis and were distributed into categories according to their cellular component and biological process using Ingenuity Pathway Analysis (IPA; Qiagen). The mass spectrometry proteomics data have been deposited to the ProteomeXchange Consortium via the PRIDE partner repository with the dataset identifier PXD014490. ${ }^{28}$

\section{9 | Immunofluorescence and confocal microscopy}

Paraformaldehyde (4\%; VWR) fixed platelets were centrifuged onto poly-I-lysine coverslips (VWR; $600 \mathrm{~g}, 5 \mathrm{~min}$ ), permeabilized with $0.2 \%$ Triton, $2 \%$ donkey serum, $1 \%$ bovine serum albumin (BSA) in PBS (all Sigma) followed by incubation with primary antibodies; mouse monoclonal anti- $\alpha$-tubulin (1:200; Sigma) or rat monoclonal anti- $\alpha$-tubulin (1:200; Invitrogen), mouse monoclonal anti-TOM20 (1:500; Santa Cruz), rabbit monoclonal anti-P-selectin, rabbit polyclonal anti-fibrinogen (1:100; Thermo Fisher Scientific), rabbit monoclonal anti-complement C4 (1:200; Abcam), then secondary conjugated antibodies; anti-mouse Alexa Fluor 555 or anti-mouse Alexa Fluor 647, anti-rat Alexa Fluor 594, anti-rabbit Alexa Fluor 647 (1:500; Thermo Fisher Scientific) or Phalloidin-647 (1:100; Thermo Fisher Scientific). Samples were mounted with Prolong Diamond antifade mount (Thermo Fisher Scientific). Confocal microscopy was performed using an inverted Zeiss LSM880 with Airyscan confocal microscope; 63x objective, 1.4 Oil DICII (Zeiss). Analysis was conducted using Zen Software (2.3 SP1, Zeiss) and ImageJ (NIH). Mitochondria number and area were calculated using Image J, averaging the number and size of mitochondria of five fields of view per individual. Integrated fluorescence intensity was established using at least five fields of view, averaged from a minimum of 20 platelets per individual.

\subsection{0 | Western blotting}

Platelet subpopulations pellets $\left(1.5 \times 10^{6}\right)$ were lysed with $2 \%$ SDS and analyzed by western blotting using anti $\alpha$-tubulin (1:10 000; Sigma) or anti $\beta$-actin (1:10 000; Santa Cruz Biotechnology) and secondary anti-mouse lgG, horseradish peroxidase-linked antibody (1:10 000, Cell Signaling Technology). Densitometry was performed using Image J software.

\subsection{1 | Quantification of mitochondrial membrane potential and phosphatidylserine exposure}

Platelet subpopulations $\left(3 \times 10^{6}\right)$ were stained with CD42b-BV421 (1:300; Biolegend) in (i) $300 \mu \mathrm{l} \mathrm{MTH}$ buffer along with MitoProbe ${ }^{\mathrm{TM}}$ DilC $_{1}$ (5) (1:300; Invitrogen) or (ii) $300 \mu \mathrm{l}$ annexin $\mathrm{V}$ binding buffer stained with Annexin V-APC (1:300; Biolegend) for $20 \mathrm{~min}$. MitoProbe $^{\mathrm{TM}} \quad \operatorname{DilC}_{1}(5)$ and Annexin $\mathrm{V}$-positive events were determined by flow cytometry (BD LSRII; BD Biosciences) and analyzed using FlowJo software v.10 (TreeStar Inc).

\subsection{2 | Functional characterization of platelet subpopulations}

\subsection{1 | Platelet adhesion and spreading}

Platelet subpopulations $\left(2 \times 10^{6}\right)$ were incubated on fibrinogen $\left(100 \mu \mathrm{g} / \mathrm{ml}\right.$, Sigma) coated coverslips for $90 \mathrm{~min}, 37^{\circ} \mathrm{C}$. Adherent platelets were fixed with paraformaldehyde $(0.2 \%)$ for $10 \mathrm{~min}$, permeabilized with Triton (0.2\%) for 5 min, stained with Phalloidin-647 (1:100). Imaging captured using an inverted Zeiss LSM880 with Airyscan confocal microscope ( $>10$ fields of view per sample). Analysis was conducted using Zen Software and ImageJ; spreading stage was quantified as; i: adherent, not spread; ii: filopodia; iii: lamellipodia; iv: fully spread.

\subsection{2 | Aggregation of platelet subpopulations}

Sorted platelets $\left(2.5 \times 10^{6}\right)$ were stained with CD61-FITC or CD61APC (young and old; 1 in 100, eBioscience) and centrifuged (1000 g, $10 \mathrm{~min}$ ). The pellets were re-suspended in MTH buffer and recombined in equal proportions. Aggregation was stimulated with TRAP-6 $(25 \mu \mathrm{M})$ for $15 \mathrm{~min}\left(750 \mathrm{rpm}, 37^{\circ} \mathrm{C}\right.$; BioShake IQ, Quantifoil Instruments) and fixed with $1 \%$ formalin (Sigma). Imaging flow cytometry (ImageStream ${ }^{X}$ Mark II; Amnis) was used to measure single platelets and formed aggregates. Analysis was performed using IDEAS software (Amnis).

\subsection{3 | Quantification of calcium dynamics}

Platelet subpopulations $\left(1 \times 10^{7} / \mathrm{ml}\right)$ were incubated with Calbryte $630^{\mathrm{TM}}\left(2 \mu \mathrm{M}\right.$; Stratech) for $30 \mathrm{~min}, 37^{\circ} \mathrm{C}$ followed by staining with CD42b-BV421 (1:100; Biolegend) for $15 \mathrm{~min}$ and supplementation with $2 \mathrm{mM} \mathrm{CaCl}_{2}$. Baseline Calbryte $630^{\mathrm{TM}}$ fluorescence was recorded for $30 \mathrm{~s}$, followed by challenge with TRAP-6 $(25 \mu \mathrm{M})$ or ionomycin (10 $\mu \mathrm{M}$; Invitrogen) and subsequent recording for $2 \mathrm{~min}$. Samples were acquired on a BD LSRII using FACSDiva acquisition software, and analyzed using FlowJo software v.10.

\subsection{4 | Quantification of P-selectin expression}

Platelet subpopulations $\left(1 \times 10^{7} / \mathrm{ml}\right)$ were incubated with TRAP-6 $(25 \mu \mathrm{M})$ or PBS $\left(20 \mathrm{~min}, 37^{\circ} \mathrm{C}\right)$, stained with CD61-FITC and CD62PAPC (1:180; eBioscience) and fixed with $1 \%$ formalin. CD62Ppostive events were determined by flow cytometry (FACS Calibur, BD Bioscience) using CellQuest Software and analyzed using FlowJo software v.8. 


\subsection{5 $\mid$ Quantification of ATP release}

Sorted platelets $\left(2.5 \times 10^{6}, 45 \mu \mathrm{MTH}\right.$ buffer $)$ supplemented with fibrinogen $(1 \mathrm{mg} / \mathrm{ml})$ were incubated with TRAP-6 $(25 \mu \mathrm{M})$ for $2 \mathrm{~min}$ $\left(1200 \mathrm{rpm}, 37^{\circ} \mathrm{C}\right)$ followed by Chronolume luciferin-luciferase system reagent (Chrono-log; 2 min; 350 rpm). ATP release was determined via luminescence using a Tecan Infinite ${ }^{\circledR}$ M200 plate reader (Tecan) and quantified using ATP standards.

\subsection{6 | LC-MS/MS analysis of eicosanoid release}

Eicosanoid production was measured from the releasate of platelet subpopulations $\left(1 \times 10^{7} / \mathrm{ml}\right)$ supplemented with fibrinogen $(1 \mathrm{mg} / \mathrm{ml})$ following incubation $\left(30 \mathrm{~min}, 37^{\circ} \mathrm{C}\right.$ ) with PBS or collagen $(30 \mu \mathrm{g} / \mathrm{ml}$, Takeda). LC-MS/MS was performed at the National Institute of Environmental Health Science, North Carolina, USA as described previously. ${ }^{6}$

\subsection{3 | Statistical analyses}

Data are expressed as mean \pm SEM. Graphs and statistical analysis were generated using GraphPad Prism 8 (GraphPad Software Inc.). Statistical analyses were performed with a paired $t$-test or a one-way ANOVA with Tukey's post-test for multiple comparisons.
Correlations were assessed by simple linear regression. Significance was defined as $p<.05$.

\section{3 | RESULTS}

\section{1 | Platelets can be separated by circulatory age using cell sorting based upon thiazole orange fluorescence}

To validate assays to use in samples from healthy human individuals, we began with experiments in mice in which we could employ in vivo labelling. Temporal in-vivo antibody labelling in mice and cell sorting followed by qRT-PCR demonstrated that the newest circulating platelets ( $<24 \mathrm{~h}$ old), had significantly lower mean cycle threshold ( $\mathrm{Ct}$ ) values for ITGA2B, PF4 and TUBB1 than old platelets (2-5 days). This is consistent with the loss of megakaryocytic mRNAs as platelets age and demonstrates that the levels of these megakaryocytic mRNAs are indicators of platelet circulatory age (Figure $1 \mathrm{~A}, p<.05, n=4)$. Next, as we cannot conduct in vivo labelling in human subjects, we assessed to what extent TO staining correlated with temporal antibody staining in mice. Analysis of these experiments demonstrated significantly higher TO fluorescence in young platelets compared to older platelets (Figure 1B, $n=4)$. Following this, we sorted human platelets on the basis of TO fluorescence intensity and defined three platelet populations: young
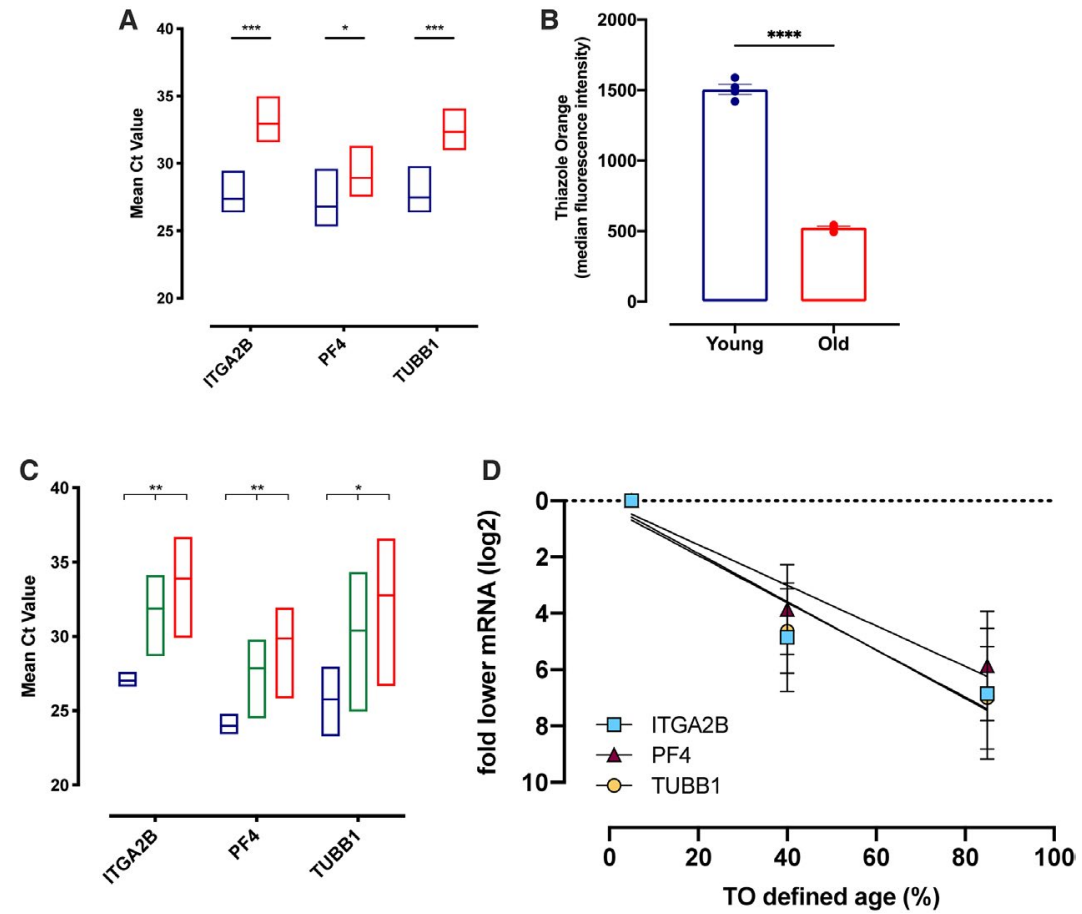

FIGURE 1 RNA expression in temporally labelled murine platelets and thiazole orange sorted human platelets. (A) qRT-PCR of plateletspecific mRNAs, ITGA2B, PF4, TUBB1, showing mean Ct value for young (blue) and old (red) murine platelets sorted on the basis of in vivo antibody labelling. (B) Thiazole orange staining in young (blue), and old (red) temporally labelled murine platelets. (C) qRT-PCR of plateletspecific mRNAs, ITGA2B, PF4, TUBB1, showing mean Ct value for young (blue), intermediate (green) and old (red) human platelets sorted on the basis of thiazole orange staining. (D) mRNA levels across TO-defined age in human sorted platelets. Data presented as min-max, with line at mean, or mean \pm SEM $\left({ }^{*} p<.05,{ }^{* *} p<.01,{ }^{* * *} p<.005,{ }^{* * *} p<.001 ; n=3-4\right)$ [Color figure can be viewed at wileyonlinelibrary.com] 
platelets (top $10 \%$ of TO fluorescence), old platelets (bottom $30 \%$; Figure S1), and for completeness intermediate-aged platelets (defined as the $50 \%$ between young and old platelets). To further validate this approach for the separation of human platelets, we conducted qRT-PCR and, as for murine platelets, confirmed that young platelets had significantly lower $\mathrm{Ct}$ values for ITGA2B, PF4, TUBB1 than both old platelets (ITGA2B, $27.0 \pm 0.3$ vs. $33.9 \pm 2.0$; PF4, $23.9 \pm 0.4$ vs. $29.9 \pm 2.0$; TUBB1, $25.8 \pm 1.4$ vs. $32.8 \pm 3.0$; young vs. old platelets; Figure $1 C$ $p<.05, n=3$ ) and intermediate-aged platelets (ITGA2B, $27.0 \pm 0.3$ vs. $31.9 \pm 1.6$; PF4, $23.9 \pm 0.4$ vs. $27.9 \pm 1.7$; TUBB1, $25.8 \pm 1.4$ vs $30.4 \pm 2.8$; young vs. intermediate platelets, $p<.05$ for all, $n=3$ ). There were highly significant correlations between TO-determined platelet age and log2 fold differences in mRNA, as determined from $\mathrm{Ct}$ values, for ITGA2B ( $\left.r^{2} 0.53, p<.03\right)$, PF4 $\left(r^{2} 0.55, p<.02\right)$ and TUBB1 $\left(r^{2}\right.$ $0.65, p<.008$ ) (Figure 1D). The levels of a further ten mRNAs relevant to platelet function were also noted to decline strongly, although for these $\mathrm{Ct}$ values $>40$ in old platelets precluded full analyses (Table S1). From these data we can conclude that our TO staining and sorting protocols allow the separation of human platelets from healthy volunteers on the basis of circulatory age as confirmed by decline in megakaryocytic mRNAs. Importantly, activation status did not change during the staining and sorting protocol (Figure S2) indicating that platelets were not adversely activated by these processes.

\section{2 | Platelet ageing is associated with a decline in total protein content}

We noted significant correlation $\left(r^{2} 0.49, p<.01, n=4\right)$ between TO-defined platelet age and protein content per platelet (young,
$8.7 \pm 2.6 \mathrm{pg}$; intermediate-aged, $6.6 \pm 0.7 \mathrm{pg}$; old, $4.7 \pm 1.2 \mathrm{pg}$ Figure $2 \mathrm{~A}$ ). In addition, there were strong correlations between total protein content per platelet and log2 fold differences in mRNA, determined from Ct values, for ITGA2B $\left(r^{2} 0.55, p<.02\right)$, PF4 $\left(r^{2} 0.57, p<.02\right)$ and TUBB1 $\left(r^{2} 0.68, p<.006\right)$ (Figure $\left.2 B\right)$. Notably these correlations are incompatible with the notion that mRNA and protein vary by platelet size rather than age, as protein varies across the TO-defined populations linearly and mRNA by powers of 2. As further confirmation, immunofluorescence revealed there was no difference in the cross-sectional area of our sorted young and old platelets (young platelets, $8.9 \pm 0.2 \mu \mathrm{m}^{2}$; old platelets, $8.5 \pm 0.5 \mu \mathrm{m}^{2}$; Figure $2 \mathrm{C}, p>.05$, $n=4)$.

\subsection{Proteomic analysis identified differences in proteins affecting fundamental biological processes}

Proteomic analysis identified 583 proteins within the sorted platelets (Table S2) of which 94 proteins were significantly modulated among the three subpopulations ( $p<.05$; Table S3). Targeted analysis between young and old platelets identified relative differences in the levels of 78 proteins (Table 1, Figure 3A).

Ingenuity Pathway Analysis predicted an association between the 78 altered proteins and 28 biological processes and functions (Figure 3B). Twenty-two of these processes were predicted as higher in young platelets including hemostasis, calcium flux, as well as transmembrane potential of mitochondria. The remaining six functions were predicted as higher in old platelets including apoptosis and senescence (Figure 3B).

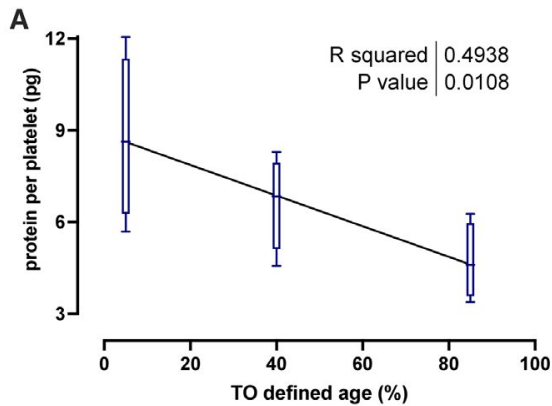

C

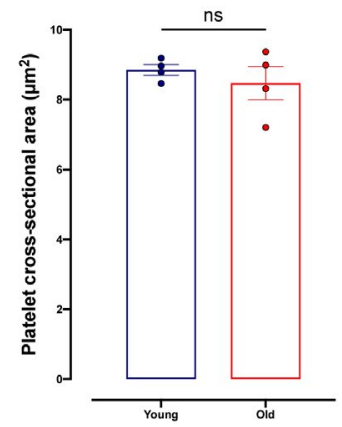

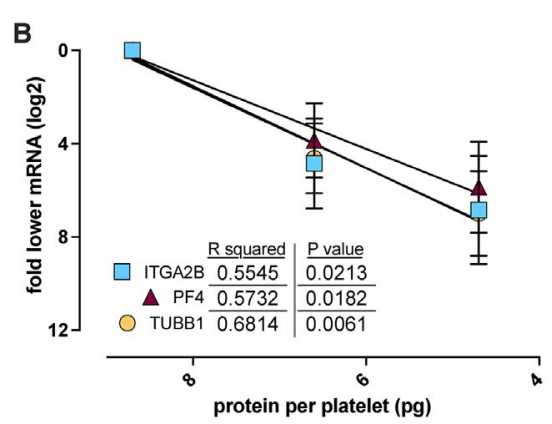

FIGURE 2 Proteomic and transcriptomic correlations in equally sized sorted platelets. (A) Quantification of protein content per platelet correlated with mean TO-defined 'age'. (B) Correlation between protein content and log-2 fold decreases of individual mRNAs ITGA2B, PF4 and TUBB1. (C) Quantification of platelet cross-sectional area in sorted young (blue) and old (red) platelets [Color figure can be viewed at wileyonlinelibrary.com] 
TABLE 1 Proteins with significantly altered expression in young and old platelets

\begin{tabular}{|c|c|c|c|c|c|}
\hline Gene name & Protein ID & Protein name & $p$ value & $\begin{array}{l}T \text { test } \\
\text { difference }\end{array}$ & $\begin{array}{l}\text { Fold } \\
\text { change }\end{array}$ \\
\hline ATP5F1B & P06576 & ATP synthase subunit beta, mitochondrial & .0001 & 2.1594 & 4.4673 \\
\hline MMRN1 & Q13201 & Multimerin-1 & .001 & 2.1423 & 4.4147 \\
\hline EEF1A1P5 & Q5VTE0 & Putative elongation factor 1 -alpha-like 3 & .0019 & 2.0238 & 4.0665 \\
\hline UBE2L3 & P68036 & Ubiquitin-conjugating enzyme E2 L3 & .0011 & 1.9264 & 3.8011 \\
\hline SH3BGRL & O75368 & SH3 domain-binding glutamic acid-rich-like protein & .0003 & 1.8976 & 3.7259 \\
\hline TMED10 & P49755 & Transmembrane emp24 domain-containing protein 10 & .002 & 1.857 & 3.6225 \\
\hline F5 & P12259 & Coagulation factor $\mathrm{V}$ & .0033 & 1.8523 & 3.6108 \\
\hline STIM1 & Q13586 & Stromal interaction molecule 1 & .0038 & 1.8354 & 3.5687 \\
\hline NNT & Q13423 & NAD (P) transhydrogenase, mitochondrial & .0096 & 1.7825 & 3.4402 \\
\hline RPN2 & P04844 & $\begin{array}{l}\text { Dolichyl-diphosphooligosaccharide--protein } \\
\text { glycosyltransferase subunit } 2\end{array}$ & .0237 & 1.7788 & 3.4314 \\
\hline CS & B4DJV2 & Citrate synthase & .0063 & 1.7694 & 3.4091 \\
\hline PRKCB & P05771 & Protein kinase $C$ beta type & .0139 & 1.7633 & 3.3947 \\
\hline HSP70-10 & P61604 & $10 \mathrm{kDa}$ heat shock protein, mitochondrial & .0074 & 1.7607 & 3.3886 \\
\hline SELPLG & Q5R345 & P-selectin & .0188 & 1.7563 & 3.3783 \\
\hline PPP2R1A & P30153 & $\begin{array}{l}\text { Serine/threonine-protein phosphatase } 2 \mathrm{~A} 65 \mathrm{kDa} \text { regulatory } \\
\text { subunit A alpha isoform }\end{array}$ & .0042 & 1.7558 & 3.3771 \\
\hline EMILIN1 & Q9Y6C2 & EMILIN-1 & .0104 & 1.7097 & 3.2709 \\
\hline GPD2 & P43304 & Glycerol-3-phosphate dehydrogenase, mitochondrial & .0147 & 1.7072 & 3.2653 \\
\hline ITGB3 & P05106 & Integrin beta-3 & .0086 & 1.7001 & 3.2492 \\
\hline RTN1 & Q16799 & Reticulon-1 & .0032 & 1.6921 & 3.2313 \\
\hline TGFB1 & P01137 & Transforming growth factor beta-1 proprotein & .0153 & 1.6856 & 3.2167 \\
\hline CMTM5 & C9JAI6 & CKLF-like MARVEL transmembrane domain-containing protein 5 & .0144 & 1.6814 & 3.2074 \\
\hline CAPN1 & P07384 & Calpain-1 catalytic subunit & .0104 & 1.6751 & 3.1934 \\
\hline ARHGDIB & P52566 & Rho GDP-dissociation inhibitor 2 & .0031 & 1.6682 & 3.1782 \\
\hline EIF4A1 & P60842 & Eukaryotic initiation factor $4 \mathrm{~A}-\mathrm{I}$ & .0255 & 1.6644 & 3.1698 \\
\hline SLC25A5 & P05141 & ADP/ATP translocase 2 & .0305 & 1.663 & 3.1667 \\
\hline INF2 & Q27J81 & Inverted formin-2 & .0003 & 1.6613 & 3.1630 \\
\hline ESYT1 & Q9BSJ8 & Extended synaptotagmin-1 & .0247 & 1.6532 & 3.1453 \\
\hline ITGA2B & P08514 & Integrin alpha-IIb & .0242 & 1.652 & 3.1427 \\
\hline PPBP & P02775 & Platelet basic protein & .022 & 1.6386 & 3.1136 \\
\hline RASGRP2 & Q7LDG7 & RAS guanyl-releasing protein 2 & .0292 & 1.6363 & 3.1087 \\
\hline ME2 & AOA1W2PQH3 & Malic enzyme & .0014 & 1.6359 & 3.1078 \\
\hline ARHGAP18 & Q8N392 & Rho GTPase-activating protein 18 & .0127 & 1.629 & 3.0930 \\
\hline MYL12A & P19105 & Myosin regulatory light chain $12 \mathrm{~A}$ & .0406 & 1.6141 & 3.0612 \\
\hline
\end{tabular}


TABLE 1 (Continued)

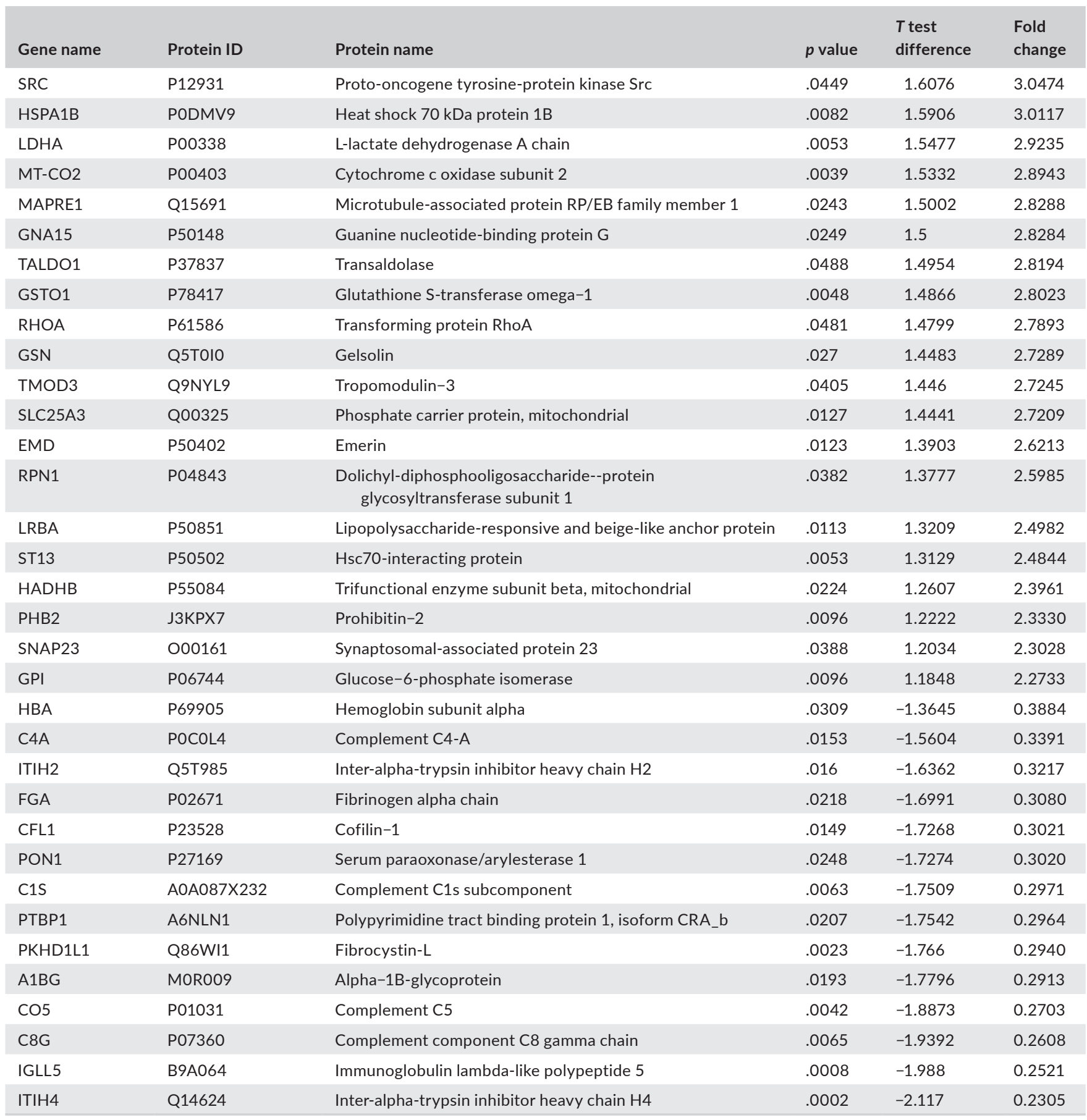

\subsection{Old platelets have reduced mitochondrial number and activity}

Proteomic analysis demonstrated a relative reduction in the levels of key mitochondrial proteins in old platelets, notably citrate synthase and ADP/ATP translocase 2 (Table 1). Further investigation using immunofluorescence and confocal microscopy for the mitochondrial protein, TOM20, established that the reduction in mitochondrial proteins was accompanied by a decrease in the number of mitochondria per platelet from $11 \pm 1$ in young platelets to $5 \pm 1$ in old platelets (Figure $4 \mathrm{~A}-\mathrm{C} ; p<.05, n=4$ ). This observed reduction was not due to mitochondrial fusion as there was no change in mitochondrial cross-sectional area (young platelets, $177 \pm 10 \mathrm{~nm}^{2}$; old platelets, $156 \pm 20 \mathrm{~nm}^{2}$; Figure 4D; $p<.05$, $n=4)$. In agreement with the IPA, we identified a reduction in mitochondrial membrane potential in old platelets compared to young platelets (Figure 4E,F; $p<.05, n=4$ ). Furthermore, phosphatidylserine exposure, commonly associated with a reduction in mitochondrial membrane potential, was higher basally in old platelets as indicated by higher levels of annexin V binding ( $20 \pm 4 \%$ vs. $3 \pm 1 \%$ positive in old vs. young platelets; Figure $4 \mathrm{G}-\mathrm{I} ; p<.05$, $n=6)$. 

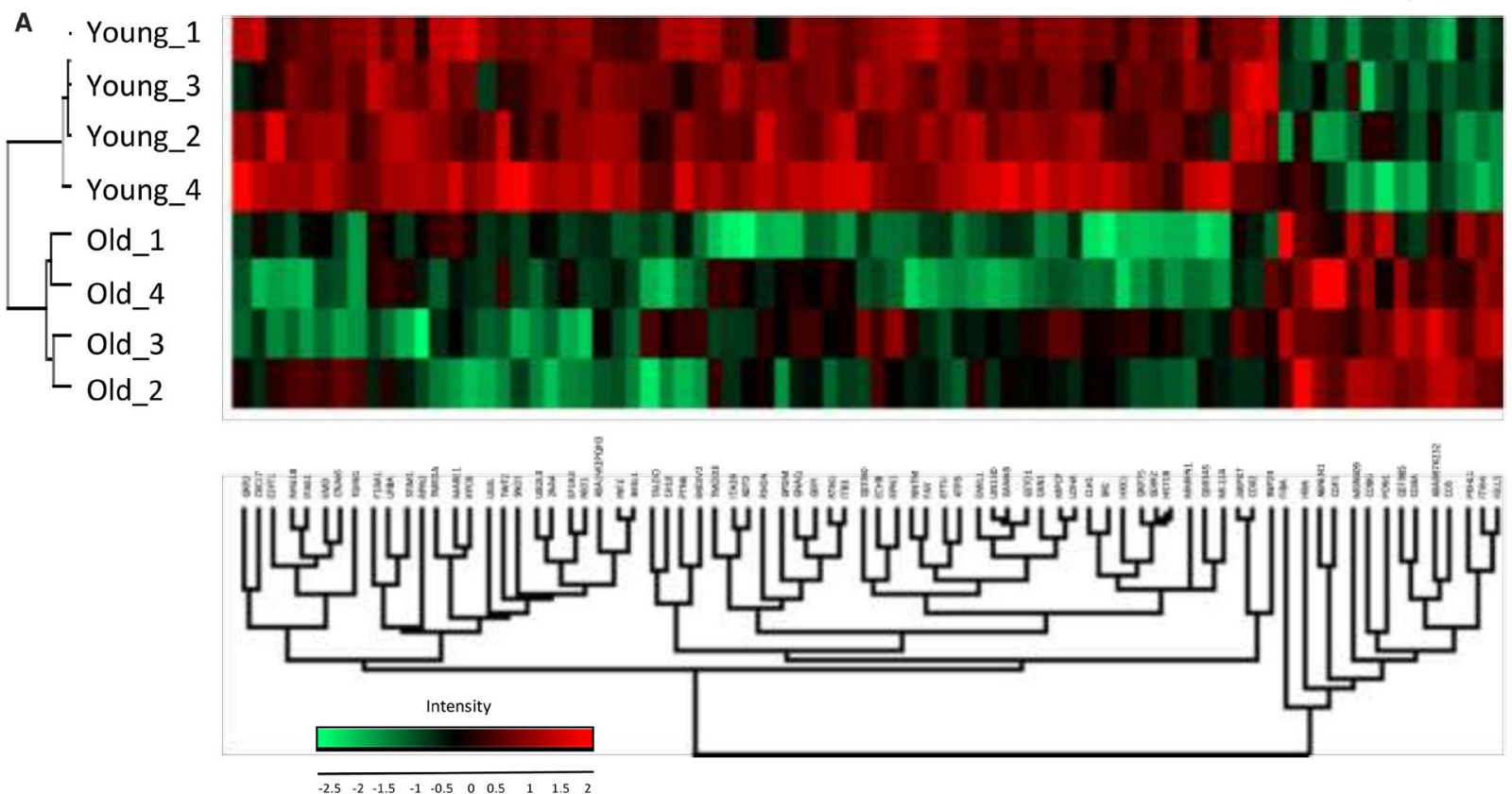

B

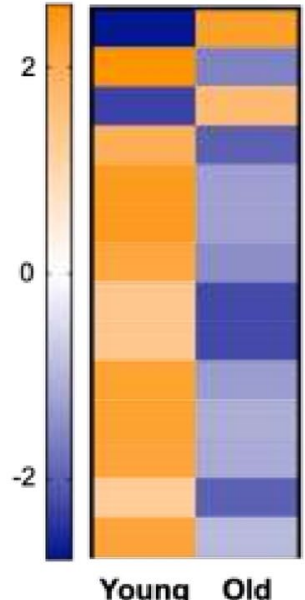

Young Old
Necrosis

Cell viability

Apoptosis

Activation of cells

Organization of cytoplasm

Organization of cytoskeleton

Flux of $\mathrm{Ca} 2+$

Binding of blood platelets

Hemostasis

Cell survival

Cell movement

Endocytosis

Binding of protein binding site

Microtubule dynamics

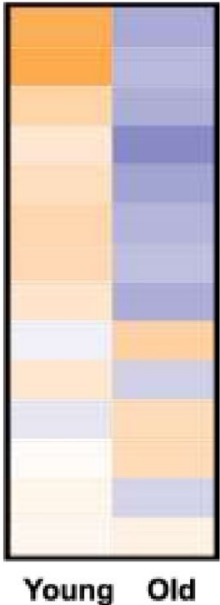

Formation of cellular protrusions

Migration of cells

Transmembrane potential of mitochondria

Formation of actin filaments

Formation of filaments

Formation of lamellipodia

Adhesion of blood cells

Binding of blood cells

Binding of myeloid cells

Quantity of $\mathrm{Ca} 2+$

Senescence of cells

Binding of professional phagocytic cells

Formation of cytoskeleton

Production of reactive oxygen species

FIG URE 3 Proteomic and Ingenuity Pathway Analysis of young and old platelets. (A) Hierarchical clustering heatmap showing the 78 proteins that were significantly modulated between young and old platelets; for each protein the log2 (intensity) was measured in samples from four individuals (noted 1-4) with low content indicated in green and high content indicated in red. (B) Ingenuity pathway analysis showing biological functions predicted to be affected by the differential protein content of young platelets relative to old platelets. The biological processes are listed according to their Z-score: orange indicates a predicted upregulation, blue a predicted downregulation. Data presented as mean z-score $(n=4)$ [Color figure can be viewed at wileyonlinelibrary.com]

\subsection{Old platelets have an altered cytoskeleton resulting in reduced platelet spreading}

Proteomics also indicated a reduction in the amount of a number of cytoskeletal binding proteins suggesting age related alterations to cytoskeletal structure (Table 1). Immunofluorescence demonstrated a significant decrease in the fluorescence intensity for $\alpha$-tubulin (2435 \pm 354 arbitrary units (AU) vs. $1034 \pm 79 \mathrm{AU}$; Figure $5 \mathrm{~A}-\mathrm{C} ; \mathrm{p}<.05, n=4)$ and F-actin $(2166 \pm 110 \mathrm{AU}$ vs.
$1364 \pm 139 \mathrm{AU}$; Figure 5D-F; $p<.05, n=5$ ) in young vs. old platelets, respectively. Furthermore, western blotting confirmed the reduction in the expression of $\alpha$-tubulin and $\beta$-actin (Figure S3A-B). Notably, the reduction in cytoskeletal proteins was not accompanied by a change in the cross-sectional area of resting platelets (Figure 2C).

Following spreading on fibrinogen, old platelets showed a marked reduction in their spread area $(24.2 \pm 2.8 \mu \mathrm{m}$ vs. $7.9 \pm 0.6 \mu \mathrm{m}$; young vs. old platelets respectively; $p<.05, n=4$; Figure 5G-I). Categorization of spreading stage demonstrated that old platelets 
A

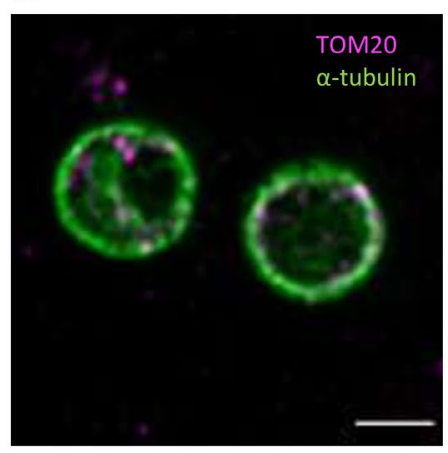

B

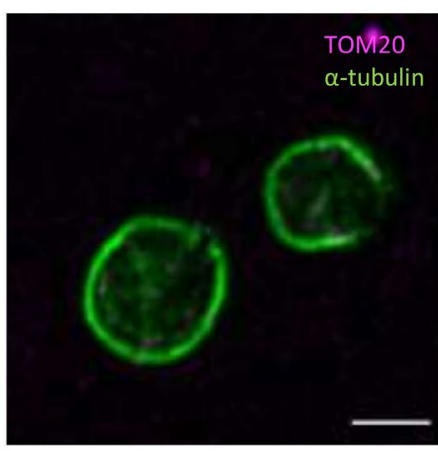

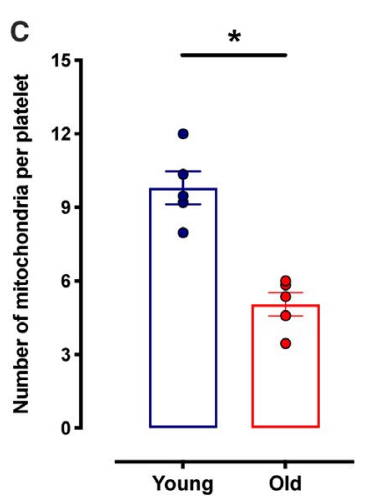
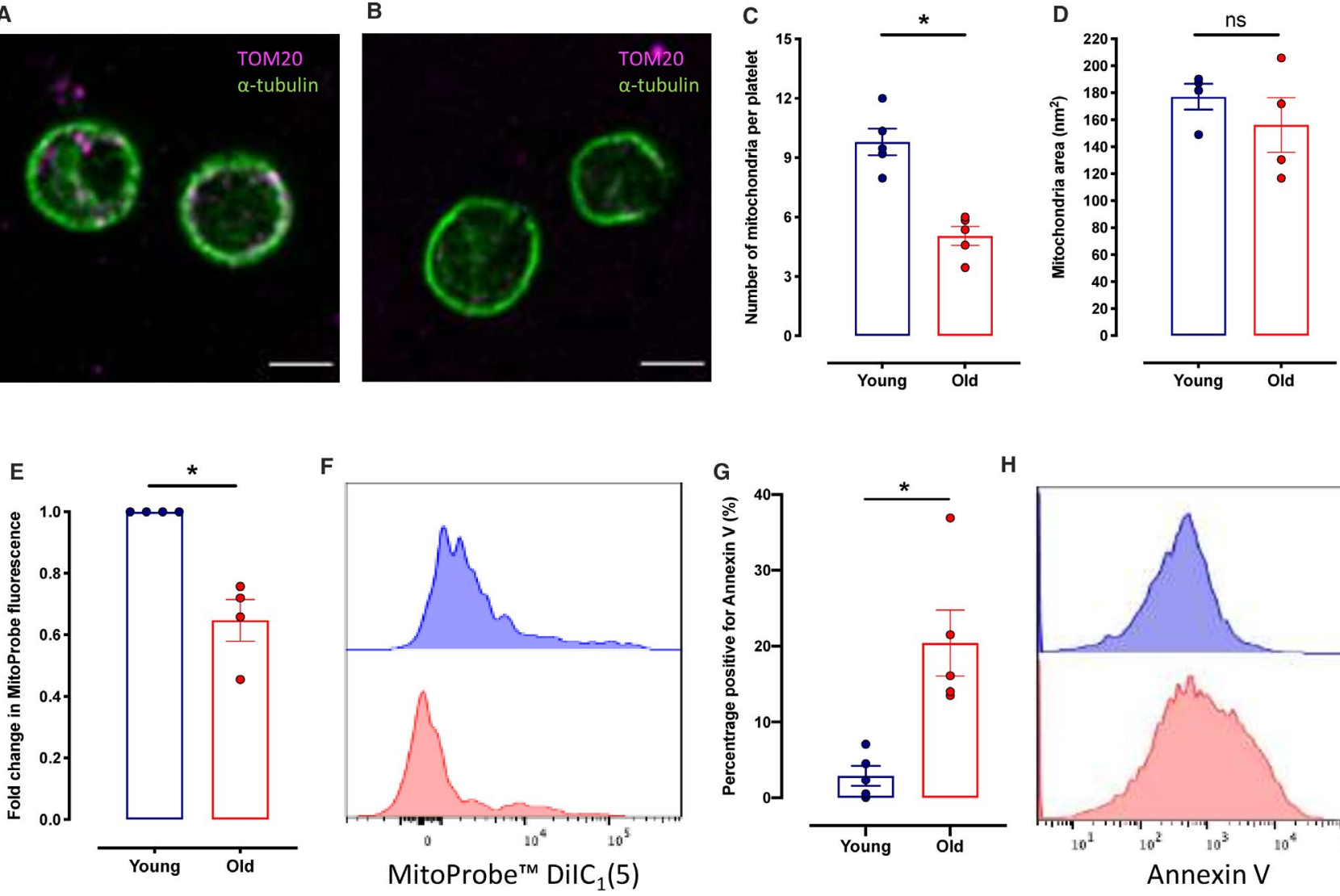

H
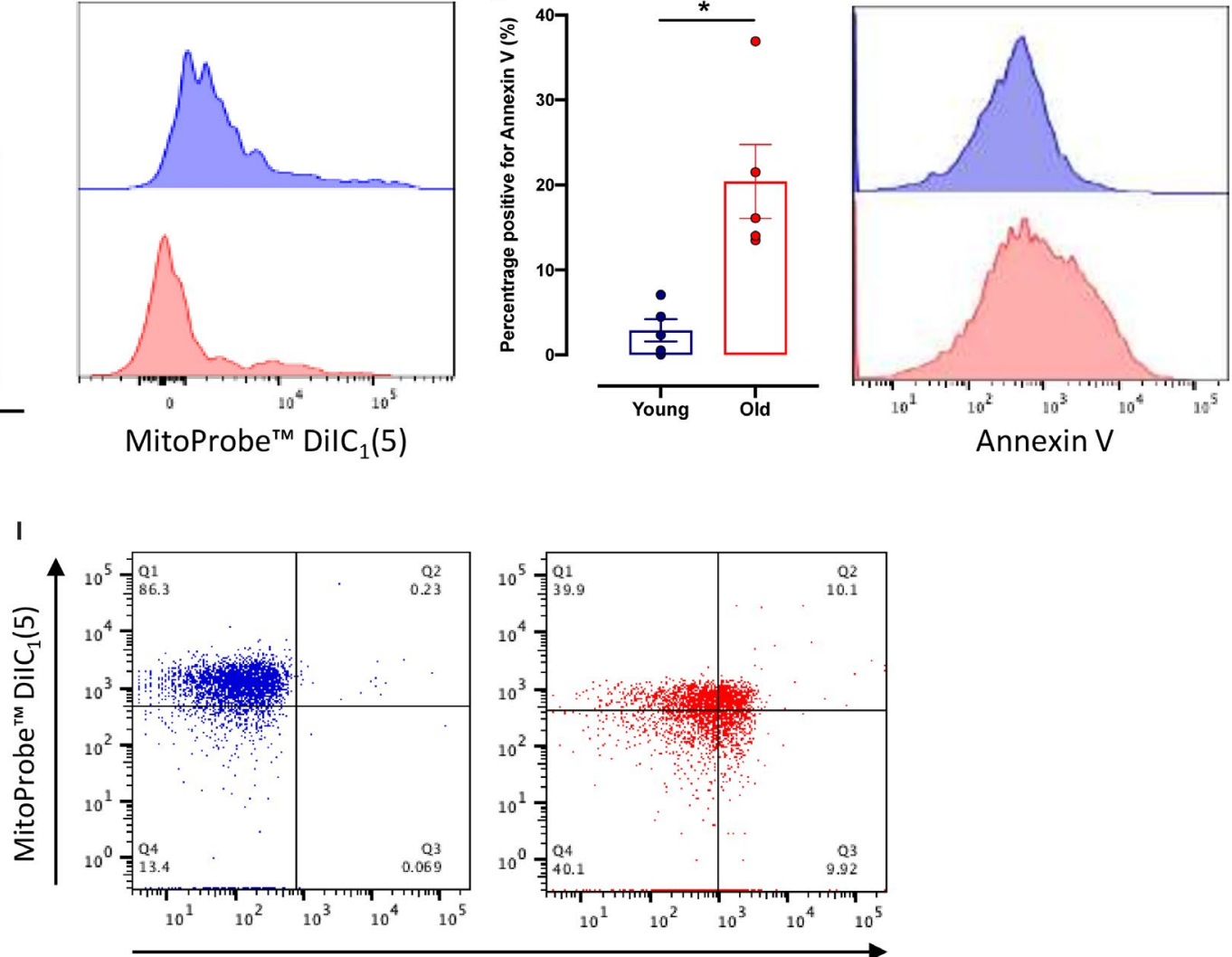

Annexin V

FIGURE 4 Analysis of mitochondria characteristics in young and old platelets. (A and B) Representative confocal microscopy images (Zeiss LSM880 with Airyscan; 63× objective, 1.4 Oil DICII) showing mitochondria; TOM20 (magenta) and $\alpha$-tubulin (green) in (A) young platelets and (B) old platelets, scale bar represents $2 \mu \mathrm{m}$. (C) Quantification of the average number of mitochondria per platelet. (D) Quantification of cross-sectional mitochondrial area in young and old platelets. (E) Quantification of mitochondrial membrane potential in young and old platelets. (F) Representative histogram of MitoProbe ${ }^{\mathrm{TM}}$ DilC1(5) fluorescence in young (blue) and old (red) platelets. (G) Quantification of phosphatidylserine exposure; annexin $\vee$ binding. $(\mathrm{H})$ Representative histogram of annexin $\mathrm{V}$ binding in young (blue) and old (red) platelets. (I) Representative dot plots showing MitoProbe DilC1(5) fluorescence vs. Annexin V binding in young (blue) and old (red) platelets. Data presented as mean $\pm \operatorname{SEM}\left({ }^{*} p<.05,{ }^{* * *} p<.005, n=4\right)$ [Color figure can be viewed at wileyonlinelibrary.com]

were able to form filopodia but unlike young platelets did not transition into lamellipodia and fully spread (Figure 5J). Furthermore, the reduction in spreading was accompanied by a decrease in the percentage of platelets forming actin nodules ( $63 \pm 1 \%$ vs. $24 \pm 1 \%$; young vs. old platelets; $p<.05, n=4$; Figure S3C-E).

\section{6 | Platelet ageing is associated with alterations in intracellular protein components}

Proteomics also identified a relative increase in the levels of a small number of circulating proteins as platelets age (complement C5, 
C1s and C4a, and fibrinogen alpha chain; Table 1). Microscopy confirmed an increased abundance of complement $\mathrm{C} 4$ and fibrinogen in old platelets (respectively, $661 \pm 150 \mathrm{AU}$ vs. $1519 \pm 181 \mathrm{AU}$ and $580 \pm 93 \mathrm{AU}$ vs. $961 \pm 179 \mathrm{AU}$, in young vs. old platelets; Figure 6C,F; $p<.05, n=4$ ) localized both at the cell periphery and within the cytoplasm consistent with internalization (Figure 6A-F).

\section{7 | Platelet ageing is associated with a reduction in activation and secretory pathways}

Imaging flow cytometry of fabricated mixed populations of $50 \%$ young and $50 \%$ old platelets demonstrated that young platelets responded more rapidly to stimulation, forming the core of aggregates with old platelets binding to the periphery (Figure 7A). Young platelets were present in $95 \pm 2 \%$ of aggregates compared with $42 \pm 6 \%$ of old platelets (Figure 7B; $p<.05, n=3$ ). Notably, $57 \pm 6 \%$ of aggregates were composed exclusively of young platelets but only $4 \pm 2 \%$ were composed exclusively of old platelets (Figure 7C; $p<.05, n=3)$. These different aggregatory responses were associated with further distinct functional differences. Young platelets demonstrated a stronger increase in intracellular calcium following exposure to TRAP- 6 than old platelets (AUC; $7712 \pm 1684$ AU vs. $2532 \pm 1221 \mathrm{AU}$; Figure 7D,E; $p<.05, n=4$ ). Similarly, ionomycin elicited a significantly stronger calcium response in young platelets than old platelets (AUC; $69830 \pm 12864$ AU vs. $27973 \pm 10195 \mathrm{AU}$; Figure 7F,G; $p<.05, n=4$ ) suggesting young platelets have larger calcium stores. Consistent with a reduction in activation pathways associated with ageing, old platelets had reduced granule secretion indicated by a significant reduction in P-selectin expression and ATP release (respectively, $0.39 \pm 0.05$ and $0.36 \pm 0.04$-fold changes compared to young platelets; Figure $7 \mathrm{H}-\mathrm{I} ; p<.05, n=5$ ). This reduction in P-selectin exposure may be due to a decline in P-selectin content identified in the proteomics (Table 1) and immunofluorescence (1061 \pm 59 vs. $524 \pm 76$ in young vs. old platelets; Figure 6G-I; $p<.05, n=4 ;$ ). Furthermore, synthesis and release of eicosanoids in response to collagen was altered between the two platelet subpopulations; old platelets released significantly lower quantities of thromboxane $A_{2}$, as measured by thromboxane $B_{2}$ production, prostaglandin $E_{2}$ and 12-hydroxyeicosatetraenoic acid than young platelets (Figure $7 \mathrm{~J}-\mathrm{L} ; p<.05, n=8$ ).

\section{4 | DISCUSSION}

Changes in the age profile of platelet populations have been associated with many disease states and increased risk of thrombotic events. However, to date there has been very limited systematic investigation into the changes that platelets undergo as they age naturally. To address this need we have isolated, phenotyped and functionally characterized platelets as they age within the healthy human circulation.

To separate human platelets by age, we used TO fluorescence intensity as a surrogate marker of mRNA content, corroborating the relevance of this to platelet ageing by determining the levels of particular megakaryocyte-derived platelet-specific mRNAs with qRT-PCR. This approach was validated in mice using temporal antibody labelling and is supported by recent research using nucleic acid dye staining with TO and SYTO13 to sort platelet subpopulations for transcriptomic analyses. ${ }^{29,30}$ We found highly significant correlations between the TOdetermined platelet age and platelet levels of mRNA for ITGA2B, PF4, TUBB1, and between TO-determined platelet age and total platelet protein; the former being a log2 function and the latter a linear relationship.

It was particularly notable that as platelets aged there was a marked reduction in total protein content, such that old platelets had lost almost half of the protein present in young platelets. As platelets are anucleate, with a limited translational capacity, this is perhaps unsurprising and could be explained by protein degradation due to basal cellular processes and release of proteins, perhaps en-

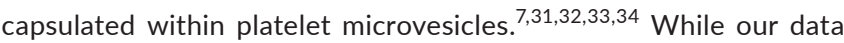
show a large general loss of proteins, this does not mean that individual proteins are not more subtly regulated. Platelets have the capacity to replenish their protein levels through endocytosis via the open canalicular system, as well as through limited protein synthesis. ${ }^{35,36}$ The latter of these processes can be engaged in response to stimulation, suggesting a controlled mechanism of synthesis to support the activation process, that might help counter the general protein loss. ${ }^{32,37}$ Given the rate of mRNA decay in platelets, ongoing protein synthesis may perhaps occur primarily within the first few days of platelet lifespan. ${ }^{9}$

We identified 583 proteins in our proteomic analysis and established significant differences in the levels of 78 proteins between young and old platelets. These differences were determined against the general loss of proteins noted above and so demonstrate particular variations rather than general changes. There were 64 proteins that compared to general proteins were significantly lower in old platelets than young platelets, indicating accelerated loss during ageing. A further 14 proteins were proportionately more abundant in old platelets, indicating selective retention, synthesis, or uptake from the circulation. Among the proteins which demonstrated accelerated loss in old platelets there was a particular signal for those involved in dynamic processes, such as in mitochondria (12 proteins) and the cytoskeleton ( 6 proteins). ${ }^{4,38}$ Ingenuity pathway analyses of the significantly modulated proteins predicted strong associations between older platelet age and reductions in cell activation and calcium flux, cytoskeletal organization, microtubule dynamics, formation of filaments and lamellipodia, binding of platelets and hemostasis, which we substantiated in the functional studies discussed below. The pathway analyses also associated old platelets to reduced cell viability and increased necrosis, apoptosis, and senescence.

Platelets are highly metabolically active cells, containing a small number of mitochondria, which under basal conditions generate approximately $40 \%$ of their ATP through oxidative phosphorylation. ${ }^{39,40}$ Following stimulation the energy demand on the platelet increases, causing an enhancement of oxidative phosphorylation. ${ }^{41}$ Our analyses demonstrated that the loss of multiple mitochondrial and metabolic proteins was associated with the loss of more than 

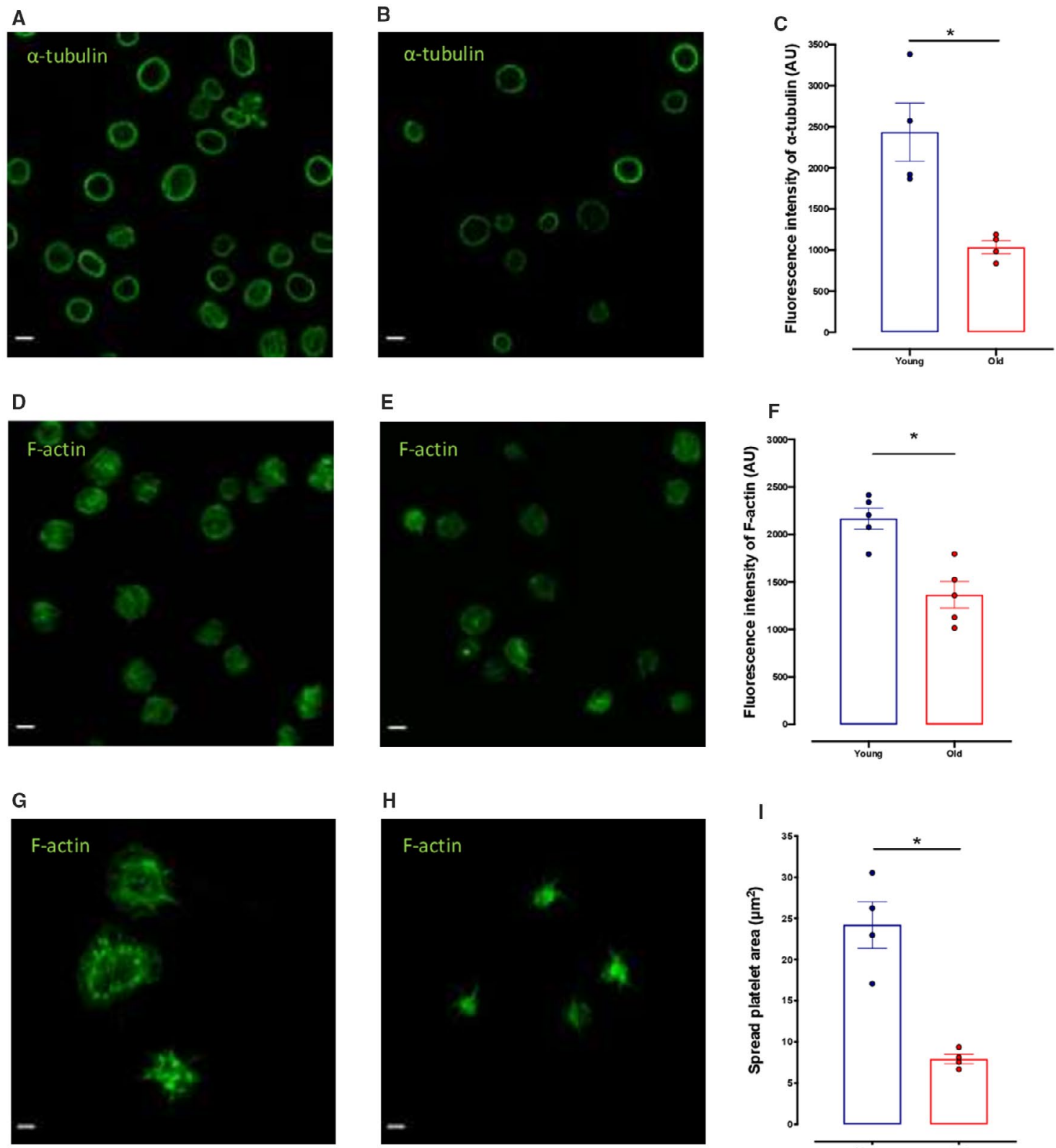

H
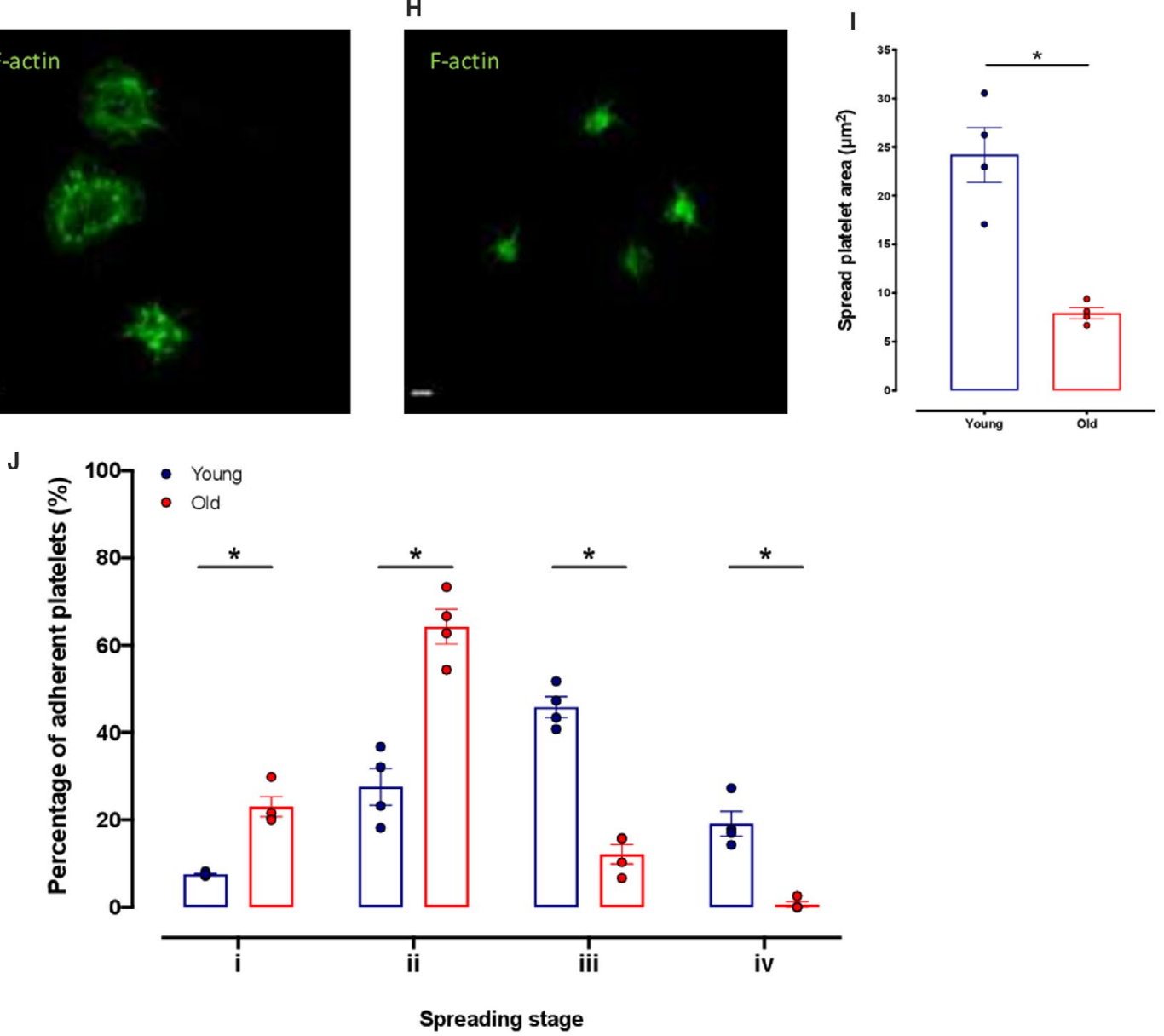
FIGURE 5 Analysis of platelet cytoskeletal structure. (A and B) Representative confocal microscopy images visualizing $\alpha$-tubulin in (A) young and (B) old platelets. (C) Quantification of $\alpha$-tubulin fluorescence intensity. (D and E) Representative confocal microscopy images visualizing F-actin in (D) young and (E) old platelets. (F) Quantification of F-actin fluorescence intensity. (G and H) Representative confocal microscopy images of platelets spread on fibrinogen stained with F-actin in (G) young and (H) old platelets. (I) Quantification of spread platelet area. $(\mathrm{J})$ Quantification of stage of platelet spreading: i, adhered but not spread; ii, filopodia; iii, lamellipodia; and iv, fully spread in young (blue) and old (red) platelets. Images acquired on a Zeiss LSM880 with Airyscan confocal microscope; 63x objective, 1.4 Oil DICII, scale bar represents $2 \mu \mathrm{m}$; data presented as mean \pm SEM $\left({ }^{*} p<.05, n=4\right)$ [Color figure can be viewed at wileyonlinelibrary.com]

half the mitochondria in old platelets. The mechanisms leading to reduced mitochondria number as platelets age are unclear, but recent research has highlighted the importance of the inner mitochondrial membrane mitophagy receptor, prohibitin 2, in mediating mitophagy in platelets. Interestingly, we identified a significant reduction in the abundance of prohibitin 2 in old platelets, suggesting accelerated degradation following from an increase in mitophagy pathways and thus accelerated consumption. ${ }^{42}$

Cytoskeletal rearrangement is intimately linked to activation and adhesion pathways, thus the reductions in cytoskeletal proteins such as emerin, gelsolin, and twinfilin-2 identified via proteomics, and of $\alpha$-tubulin and $\beta$-actin demonstrated by immunofluorescence and western blotting, will cause impairments in activation and adhesion pathways in old platelets. During platelet activation the membranebound actin network is severed, promoting membrane expansion and the formation of protrusions. ${ }^{43}$ The subsequent assembly of actin monomers allows the protrusions to elongate forming filopodia and lamellipodia, facilitating firm adhesion. ${ }^{44}$ Consistent with the loss of the key cytoskeletal proteins, we observed that old platelets do not fully spread, arresting at the filopodia stage of adhesion, consistent with defects in the later stages of actin assembly.

In addition to an impairment in spreading capability, proteomics highlighted reductions in granule proteins and those involved in granule exocytosis suggesting defects in granule secretion associated with ageing. Indeed, we found that old platelets have diminished dense and $\alpha$-granule secretion upon activation, consistent with reports of higher P-selectin expression on activated reticulated platelets. ${ }^{45}$ Our study indicates two contributing changes in old platelets. Firstly, old platelets have reduced intracellular P-selectin levels and secondly, loss of cytoskeletal proteins together with decreases in SNAP23, part of the SNARE-fusion machinery, may cause a reduction in granule exocytosis. ${ }^{46}$

Reductions in cytoskeletal and mitochondrial proteins may also influence apoptotic pathways. Intrinsic apoptosis initiated by disruption to mitochondrial integrity has been described in platelets, highlighting the importance of mitochondrial membrane depolarization along with $B C L-X_{L}$ and $B a x / B a k$ proteins in mediating mitochondrial damage, subsequent caspase activation and phosphatidylserine exposure. ${ }^{47-51}$ Our data suggest that mitochondrial loss during normal platelet ageing may be due to an accumulation of damage triggering mitophagy pathways to remove damaged mitochondria. A key step within the mitophagy pathways is depolarization of the mitochondrial membrane, which may subsequently cause release of pro-apoptotic proteins into the platelet cytoplasm and promote the exposure of phosphatidylserine on the platelet surface. ${ }^{2,52,53}$ This exposure of phosphatidylserine would be enhanced by the loss of cytoskeletal proteins which normally maintain the asymmetric distribution of lipids within the platelet plasma membrane. ${ }^{54-56}$ With the degradation of cytoskeletal proteins, an imbalance in the membrane lipid asymmetry can arise facilitating the flipping of phosphatidylserine onto the outer leaflet. ${ }^{57}$ Exposed phosphatidylserine has been shown to be a key component of programmed cell death in platelets, acting as an 'eat-me' signal, triggering the clearance and destruction of old platelets from the circulation. ${ }^{49,52,58}$ Interestingly, platelet-specific knockout of the actin binding protein, twinfilin-2, a protein we identified in higher abundance in young platelets, results in accelerated platelet turnover due to increased clearance in the spleen, supporting a potential role for the cytoskeleton and cytoskeletal-associated proteins in the maintenance of platelet lifespan. ${ }^{59}$

Previous research into platelet ageing has produced contradictory evidence as to whether platelet size changes with age, with some groups suggesting platelet size to be independent of age whilst others report an association between mean platelet volume and thrombotic risk. ${ }^{60-66}$ Indeed, the use of TO to identify platelets containing elevated levels of mRNA as 'young' has been questioned on the basis that larger platelets may uptake more dye and so skew subsequent analysis. ${ }^{67}$ However, this cannot explain our data in healthy individuals as we noted a log2 relationship between particular megakaryocytic mRNAs and TO-determined platelet age; i.e. platelets would have to vary in size by around 32-64 fold for such a relationship to hold. Furthermore, we found no differences in the cross-sectional areas of young and old platelets. We have not, however, examined associations between platelet age and size in any pathological conditions in which different relationships may well exist. Interestingly, it was hypothesized some 40 years ago that buoyant density could be an indicator of platelet age, with the observation that high density platelets are more metabolically active. ${ }^{68}$ This idea is supported by our data in which younger platelets have higher protein content and contain more mitochondria consistent with higher density and metabolic activity. Consistent with this, our data also support the related and much more recent suggestion that mitochondria number is a better indicator of platelet age than platelet size. ${ }^{69}$

The discussion above has focused upon proteins that are decreased at accelerated rates as platelet age, however our proteomic analysis also demonstrated significant increases in the relative levels of some other proteins. These can largely be categorized as circulating proteins, including complement proteins and fibrinogen, which are most likely endocytosed as platelets circulate. Supporting this notion, research has implicated anionic phospholipids, such as phosphatidylserine, as promotors of complement protein activation. ${ }^{70,71}$ Conversely, recent transcriptomic research has indicated a relative 
A

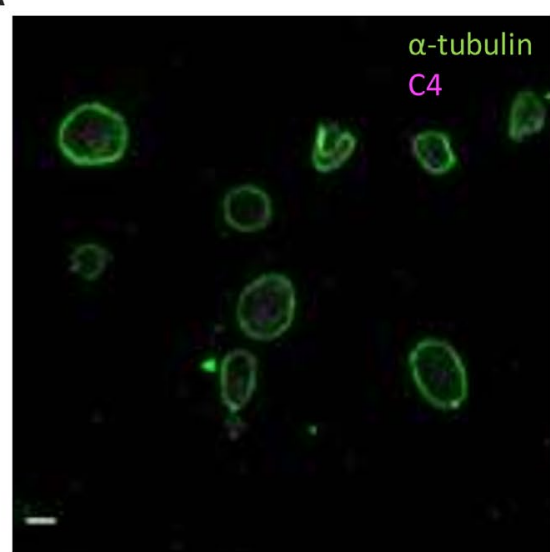

D

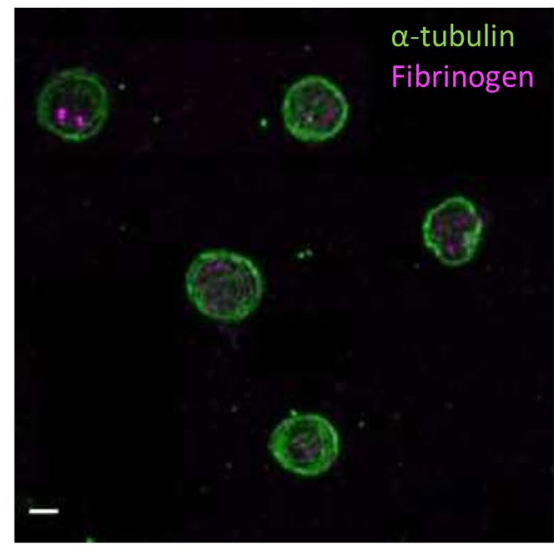

G

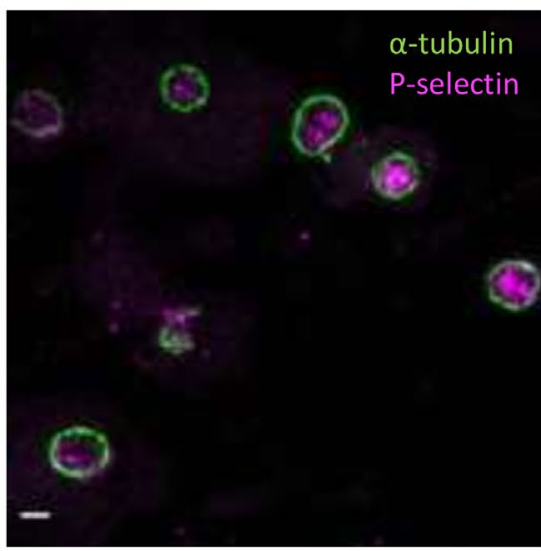

B

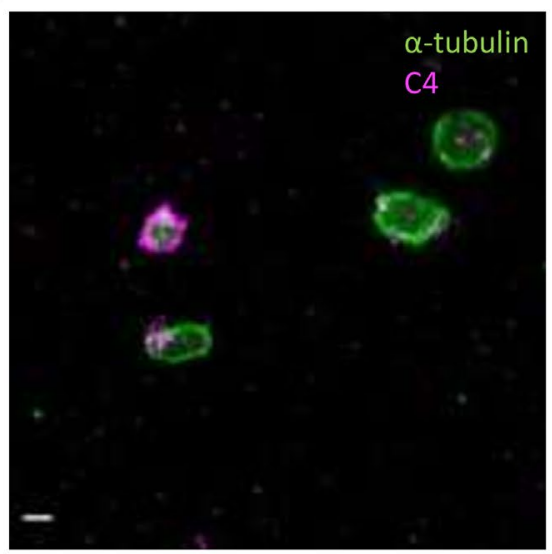

E

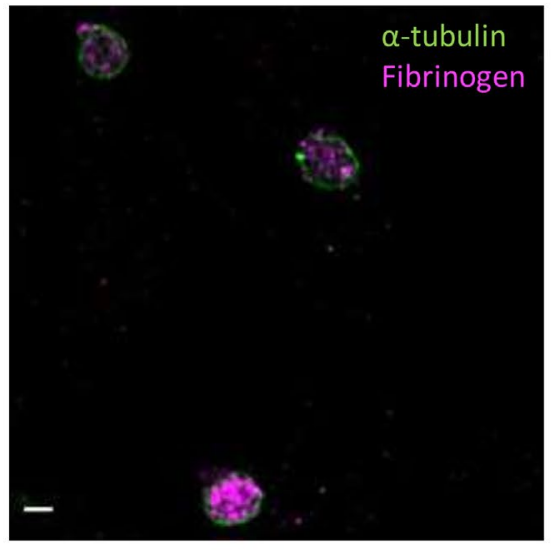

H

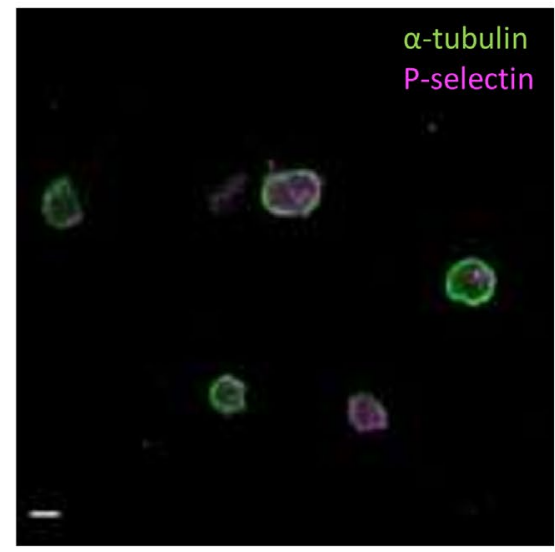

C

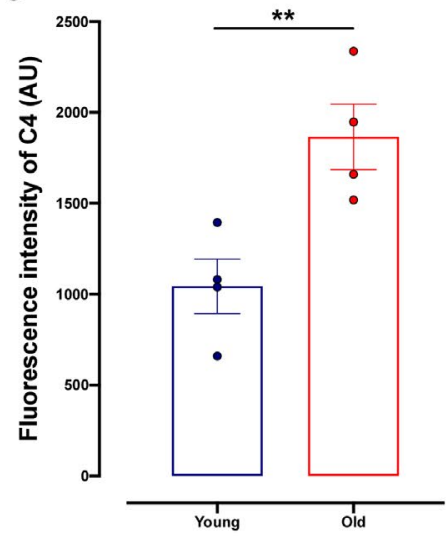

F

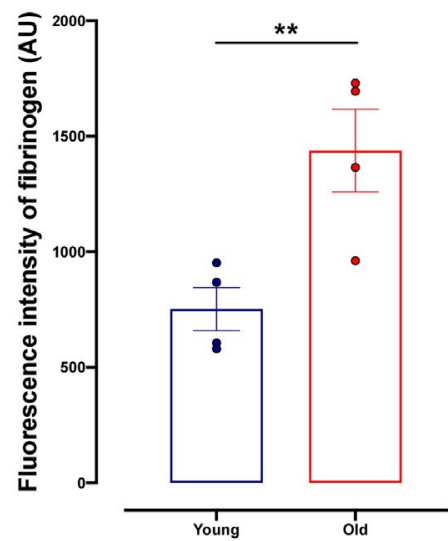

I

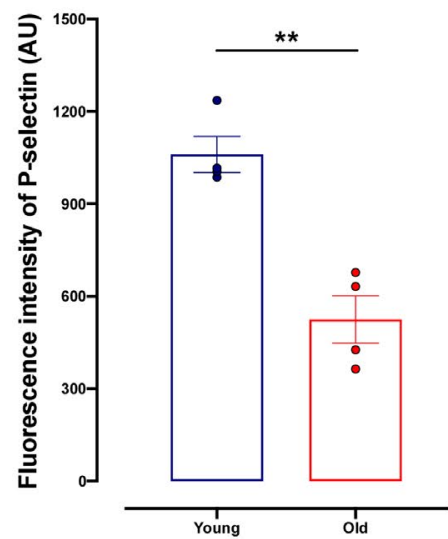

FIGURE 6 Analysis of intracellular components in young and old platelets. (A and B) Representative confocal microscopy images visualizing $\alpha$-tubulin (green) and complement protein C4 (magenta) in (A) young and (B) old platelets. (C) Quantification of complement C4 fluorescence intensity. ( $D$ and E) Representative confocal microscopy images visualizing $\alpha$-tubulin (green) and fibrinogen (magenta) in (D) young and (E) old platelets. (F) Quantification of fibrinogen fluorescence intensity. ( $G$ and $H$ ) Representative confocal microscopy images visualizing $\alpha$-tubulin (green) and P-selectin (magenta) in (G) young and (H) old platelets. (I) Quantification of P-selectin fluorescence intensity. Images acquired on a Zeiss LSM880 with Airyscan confocal microscope; 63x objective, 1.4 Oil DICII, scale bar represents $2 \mu \mathrm{m}$; data presented as mean \pm SEM $\left({ }^{* *} p<.01, n=4\right)$ [Color figure can be viewed at wileyonlinelibrary.com] 
A

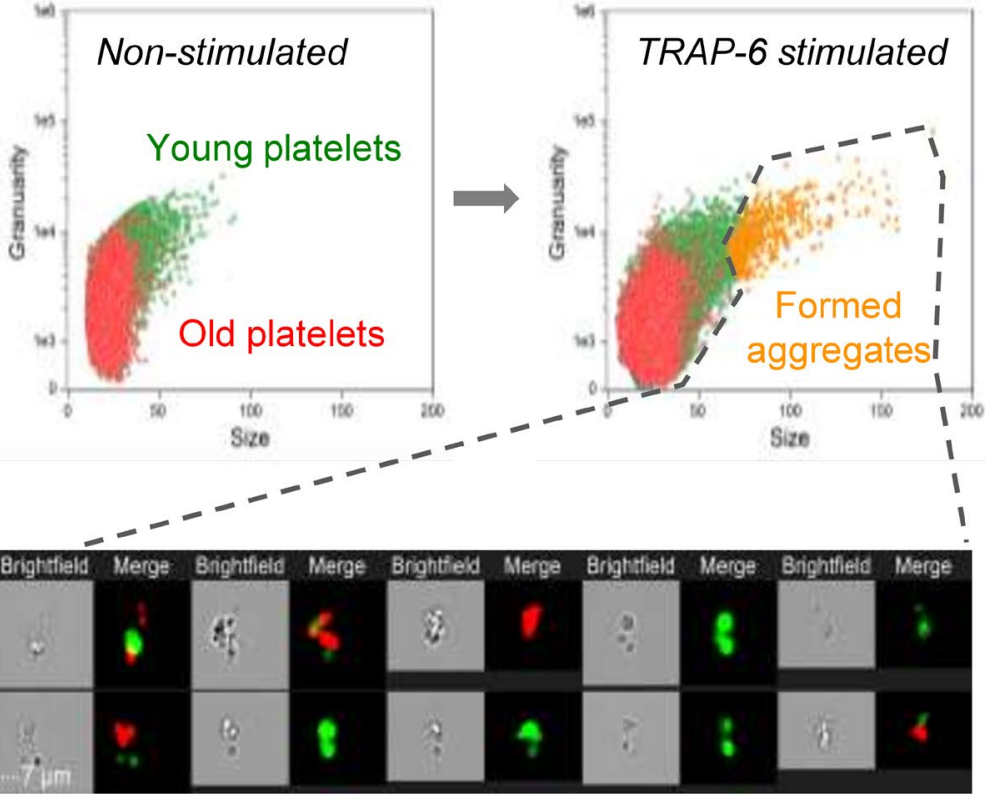

Representative images from formed aggregate gate captured by imaging flow cytometry
B

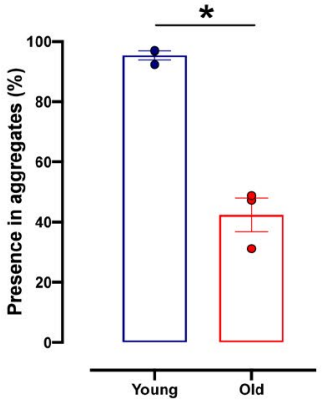

C

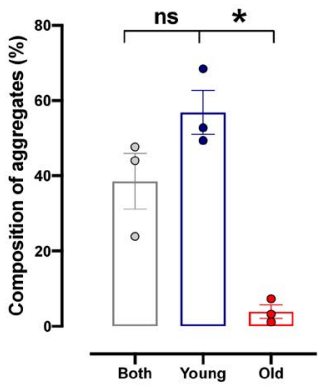

D

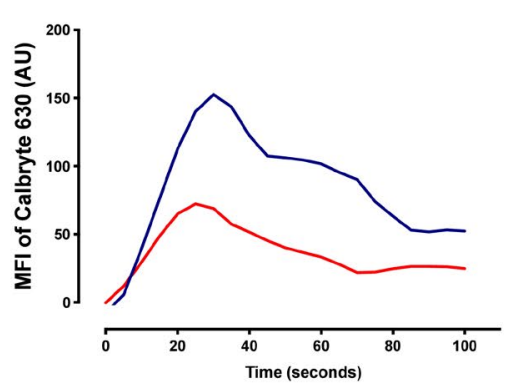

E

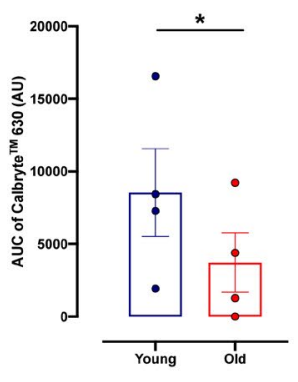

F

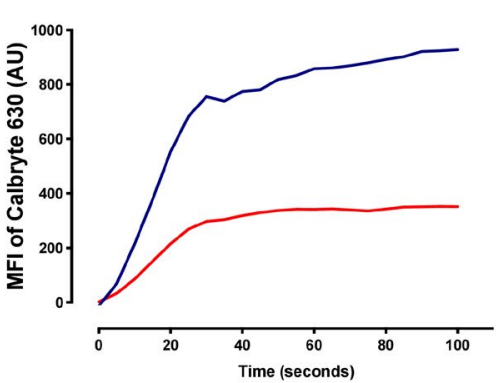

K

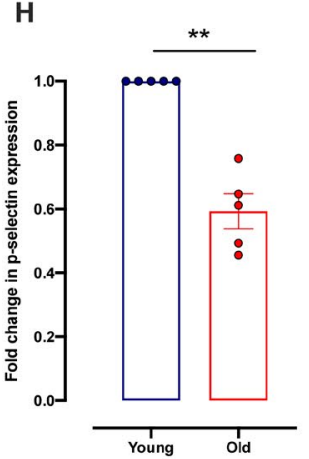

I

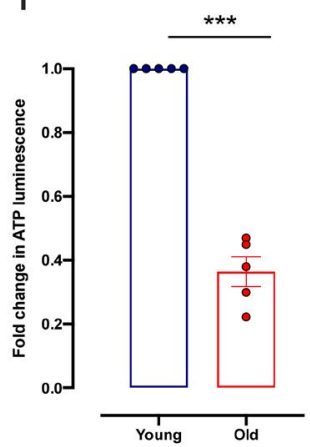

J

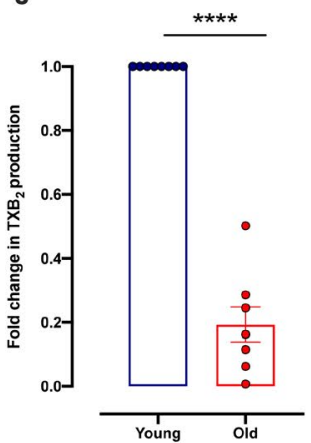

G

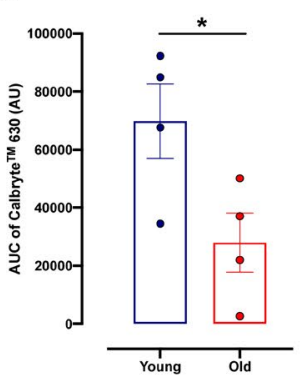

FIGURE 7 Characterization of function in young and old platelets. (A) Representative imaging flow cytometry dot plots and images showing young platelets (green) and old platelets (red) in non-stimulated and TRAP-6 stimulated samples. (B) Quantification of the percentage of young and old platelets within the formed aggregates. (C) Quantification of the composition of aggregates. (D) Representative calcium dynamic traces in young (blue) and old (red) platelets following TRAP-6 stimulation. (E) Quantification of area under the curve of the calcium trace following TRAP-6 stimulation. (F) Representative calcium dynamic traces in young (blue) and old (red) platelets following ionomycin stimulation (G) Quantification of area under the curve of the calcium trace following ionomycin stimulation. (H) Quantification of P-selectin expression following TRAP-6 stimulation fold change of old relative to young platelets. (I) Quantification of ATP release following TRAP-6 stimulation fold change of old relative to young platelets. Quantification of eicosanoid synthesis following collagen stimulation fold change of old relative to young platelets: (J) thromboxane B2; (K) prostaglandin E2 (PGE2); (L) 12-hydroxyeicosatetraenoic acid (12-HETE). Data presented as mean \pm SEM $\left({ }^{*} p<.05,{ }^{* *} p<.01,{ }^{* * *} p<.005,{ }^{* * * *} p<.001, n=3-8\right)$ [Color figure can be viewed at wileyonlinelibrary.com] 
increase in complement $\mathrm{C} 5$ transcripts in old platelets, so perhaps there is synthesis of complement proteins within platelets. ${ }^{30}$

In conclusion, our work demonstrates changes in total and relative protein content as platelets age and associated alterations in hemostatic function. We propose that young platelets are rapid hemostatic responders, due to their more robust cytoskeleton and higher mitochondria number, forming the core of aggregates and recruiting older platelets to the periphery. Old platelets have blunted hemostatic responses, accumulate circulating proteins, and bear in dicators of cells marked for clearance from the circulation. Our research provides a detailed characterization of protein and functional changes as platelets normally age within the circulation providing key information for studies of platelet function in health and disease.

\section{1 | Limitations}

Research into platelet subpopulations is still in its relative infancy and much of the work here has been performed at the technical boundaries. In particular, to minimise activation during the sorting process but also supply responsive platelets, samples were sorted at a slow flow rate for a limited time, restricting the number of platelets available for study. As a result of lower numbers of platelets used for proteomic analysis, the total number of proteins detected within these samples is lower than previously published literature. Furthermore, technical constraints on obtaining defined platelet pellets after cell sorting, meant that we were unable to perform high resolution electron microscopy to establish changes in granule number and determine alterations in other structural components.

\section{ACKNOWLEDGEMENTS}

The authors acknowledge the support the Flow Cytometry Core Facilities at the Blizard Institute and Charterhouse Square, Queen Mary University of London and the UCD Conway Institute mass spectrometry facilities.

\section{CONFLICT OF INTEREST}

The authors declare no conflicts of interest.

\section{AUTHOR CONTRIBUTION}

HEA designed the research, performed the assays, and collected data, analyzed and interpreted data, performed statistical analysis, and wrote the manuscript. MAH, MVC, and PCA designed the research, performed the assays and collected data, analyzed and interpreted data, performed statistical analysis, and revised the manuscript. SM performed the assays and collected data, analyzed data, performed statistical analysis, and revised the manuscript. MLE performed the assays and collected data, and revised the manuscript. TM and AJ performed the assays and collected data, analyzed and interpreted data, and revised the manuscript. LM and MC analyzed and interpreted data, and revised the manuscript. DCZ and $M M$ revised the manuscript. TDW designed the research, analyzed and interpreted data, and revised the manuscript.

\section{ORCID}

Harriet E. Allan (D) https://orcid.org/0000-0002-2104-4972

Melissa A. Hayman (D) https://orcid.org/0000-0003-0381-1602

Paul C. Armstrong (D) https://orcid.org/0000-0003-0904-677X

Timothy D. Warner (D) https://orcid.org/0000-0003-3988-4408

\section{TWITTER}

Harriet E. Allan @harri_allan

\section{REFERENCES}

1. Cohen J, Leeksma C. Determination of the life span of human blood platelets using labelled diisopropylfluorophosphonate. J Clin Invest. 1956;35:964-969.

2. Lebois M, Josefsson EC. Regulation of platelet lifespan by apoptosis. Platelets. 2016;27:497-504.

3. Thompson CB, Jakubowski JA. The pathophysiology and clinical relevance of platelet heterogeneity. J Am Soc Haemotology. 1988;72:1-8.

4. Burkhart JM, Vaudel M, Gambaryan S, et al. The first comprehensive and quantitative analysis of human platelet protein composition allows the comparative analysis of structural and functional pathways. Blood. 2012;120:e73-e82.

5. Machlus KR, Italiano JE. The incredible journey: from megakaryocyte development to platelet formation. J Cell Biol. 2013;201:785-796.

6. Cecchetti L, Tolley ND, Michetti N, Bury L, Weyrich AS, Gresele P. Megakaryocytes differentially sort mRNAs for matrix metalloproteinases and their inhibitors into platelets: a mechanism for regulating synthetic events. Blood. 2011;118:1903-1911.

7. Rowley JW, Schwertz H, Weyrich AS. Platelet mRNA: the meaning behind the message. Curr Opin Hematol. 2012;19:385-391.

8. Mills EW, Green R, Ingolia NT. Slowed decay of mRNAs enhances platelet specific translation. Blood. 2017;129:e38-e48.

9. Angénieux C, Maître B, Eckly A, Lanza F, Gachet C, de la Salle H. Time-dependent decay of mRNA and ribosomal RNA during platelet aging and its correlation with translation activity la Salle $\mathrm{H}$ (2016) time-dependent decay of mRNA and ribosomal RNA during platelet aging and its correlation with translation activity. PLoS One. 2016;11:148064.

10. Harrison P, Goodall AH. "Message in the Platelet" - more than just vestigial mRNA! Platelets. 2008;19:395-404.

11. Clancy L, Beaulieu L, Tanriverdi K, Freedman J. The role of RNA uptake in platelet heterogeneity. Thromb Haemost. 2017;117:948-961.

12. Kienast J, Schmitz G. Flow cytometric analysis of thiazole orange uptake by platelets: a diagnostic aid in the evaluation of thrombocytopenic disorders. Blood. 1990;75:116-121.

13. Hoffmann JJML. Reticulated platelets: analytical aspects and clinical utility formation and maturation of megakaryocytes. Clin Chem Lab Med. 2014;52:1107-1117.

14. Freitas LG, Carvalho M, das G. Dusse LMS. Reticulated platelets: how to assess them? Clin Chim Acta. 2013;422:40-41.

15. Grotto HZW. Platelet and reticulocyte new parameters: why and how to use them? Rev Bras Hematol Hemoter. 2016;38:283-284.

16. Imperiali CE, Arbiol-Roca A, Sanchez-Navarro L, et al. Reference interval for immature platelet fraction on sysmex XN haematology analyser in adult population. Biochem Medica. 2018;28:10708.

17. McBane RD, Gonzalez C, Hodge DO, Wysokinski WE. Propensity for young reticulated platelet recruitment into arterial thrombi. J Thromb Thrombolysis. 2014;37:148-154.

18. Thompson CB. Selective consumption of large platelets during massive bleeding. Br Med J. 1985;291:95-96.

19. Kakouros N, Rade JJ, Kourliouros A, Resar JR. Platelet function in patients with diabetes mellitus: from a theoretical to a practical perspective. Int J Endocrinol. 2011;2011:1-14. 
20. Mijovic R, Kovacevic N, Zarkov M, Stosic Z, Cabarkapa V, Mitic G. Reticulated platelets and antiplatelet therapy response in diabetic patients. J Thromb Thrombolysis. 2015;40:203-210.

21. Guthikonda S, Alviar CL, Vaduganathan M, et al. Role of reticulated platelets and platelet size heterogeneity on platelet activity after dual antiplatelet therapy with aspirin and clopidogrel in patients with stable coronary artery disease. J Am Coll Cardiol. 2008;52:743-749

22. Armstrong PC, Hoefer T, Knowles RB, et al. Newly formed reticulated platelets undermine pharmacokinetically short-lived antiplatelet therapies. Arterioscler Thromb Vasc Biol. 2017;37:949-956.

23. Cesari F, Marcucci R, Caporale R, et al. Relationship between high platelet turnover and platelet function in high-risk patients with coronary artery disease on dual antiplatelet therapy platelets and blood cells. Thromb Haemost. 2008;99:930-935.

24. Armstrong PC, Kirkby NS, Chan MV, et al. Novel whole blood assay for phenotyping platelet reactivity in mice identifies ICAM-1 as a mediator of platelet-monocyte interaction. Blood. 2015;126:e11-e18.

25. Wiśniewski JR, Zougman A, Nagaraj N, Mann M. Universal sample preparation method for proteome analysis. Nat Methods. 2009;6:359-362.

26. Grande R, Dovizio M, Marcone S, et al. Platelet-derived microparticles from obese individuals: characterization of number, size, proteomics, and crosstalk with cancer and endothelial cells. Front Pharmacol. 2019;10:7.

27. Tyanova S, Temu T, Sinitcyn P, et al. The perseus computational platform for comprehensive analysis of (prote)omics data. Nat Methods. 2016;13:731-740.

28. Perez-Riverol Y, Csordas A, Bai J, et al. The PRIDE database and related tools and resources in 2019: improving support for quantification data. Nucleic Acids Res. 2019;47:D442-D450.

29. Hille L, Lenz M, Vlachos A, et al. Ultrastructural, transcriptional and functional differences between human reticulated and nonreticulated platelets. J Thromb Haemost. 2020;18(8):2034-2046.

30. Bongiovanni D, Santamaria G, Klug M, et al. Transcriptome analysis of reticulated platelets reveals a prothrombotic profile. Thromb Haemost. 2019;119:1795-1806.

31. Rowley JW, Weyrich AS. Ribosomes in platelets protect the messenger. Blood. 2017;129:2343-2345

32. Lindemann S, Gawaz M. The active platelet: translation and protein synthesis in an anucleate cell. Semin Thromb Hemost. 2007;33:144-150

33. Kraemer BF, Weyrich AS, Lindemann S. Protein degradation systems in platelets. Thromb Haemost. 2013;31:920-924.

34. Pienimaeki-Roemer A, Kuhlmann K, Böttcher A, et al. Lipidomic and proteomic characterization of platelet extracellular vesicle subfractions from senescent platelets. Transfusion. 2015;55:507-521.

35. Weyrich AS, Schwertz H, Kraiss LW, Zimmerman GA. Protein synthesis by platelets: historical and new perspectives. J Thromb Haemost. 2009;7:241-246.

36. Banerjee $\mathrm{M}$, Whiteheart SW. The ins and outs of endocytic trafficking in platelet functions. Curr Opin Hematol. 2017;24:467-474.

37. Zimmerman GA, Weyrich AS. Signal-dependent protein synthesis by activated platelets new pathways to altered phenotype and function. Arterioscler Thromb Vasc Biol. 2008;28(3):s17-s24.

38. Patel-Hett S, Richardson JL, Schulze H, et al. Visualization of microtubule growth in living platelets reveals a dynamic marginal band with multiple microtubules. Blood. 2008;111:4605-4616.

39. Zharikov S, Shiva S. Platelet mitochondrial function: from regulation of thrombosis to biomarker of disease. Biochem Soc Trans. 2013:41:118-123.

40. Kramer PA, Ravi S, Chacko B, Johnson MS, Darley-Usmar VM. A review of the mitochondrial and glycolytic metabolism in human platelets and leukocytes: implications for their use as bioenergetic biomarkers. Redox Biol. 2014;2:206-210.
41. Ravi S, Chacko B, Sawada H, et al. Metabolic plasticity in resting and thrombin activated platelets. PLoS One. 2015;10:e0123597.

42. Hu L-L, Zou K, Chen Y, et al. Functional role and molecular mechanisms underlying prohibitin 2 in platelet mitophagy and activation. Mol Med Rep. 2021;23:384.

43. Shin E-K, Park H, Noh J-Y, Lim K-M, Chung J-H. Platelet shape changes and cytoskeleton dynamics as novel therapeutic targets for anti-thrombotic drugs. Biomol Ther (Seoul). 2017;25:223-230.

44. Sorrentino S, Studt J-D, Medalia O, Tanuj Sapra K. Roll, adhere, spread and contract: structural mechanics of platelet function. Eur J Cell Biol. 2015;94:129-138.

45. Lador A, Leshem-Lev D, Spectre G, Abelow A, Kornowski R, Lev EI. Characterization of surface antigens of reticulated immature platelets. J Thromb Thrombolysis. 2017:44:291-297.

46. Flaumenhaft R, Dilks JR, Rozenvayn N, Monahan-Earley RA, Feng D, Dvorak AM. The actin cytoskeleton differentially regulates plateletgranule and dense-granule secretion. Blood. 2005;105:3879-3887.

47. McArthur K, Chappaz S, Kile BT. Apoptosis in megakaryocytes and platelets: the life and death of a lineage. Blood. 2018;131:605-610.

48. Schoenwaelder SM, Yuan Y, Josefsson EC, et al. Two distinct pathways regulate platelet phosphatidylserine exposure and procoagulant function. Blood. 2009;114:663-666.

49. Mason KD, Carpinelli MR, Fletcher JI, et al. Programmed anuclear cell death delimits platelet life span. Cell. 2007;128:1173-1186.

50. Zhang H, Nimmer PM, Tahir SK, et al. Bcl-2 family proteins are essential for platelet survival. Cell Death Differ. 2007;14:943-951.

51. Leytin V, Gyulkhandanyan AV, Freedman J. Platelet apoptosis can be triggered bypassing the death receptors. Clin Appl Thromb Hemost. 2019;25:1-4.

52. Dasgupta SK, Argaiz ER, Mercado JE, et al. Platelet senescence and phosphatidylserine exposure. Transfusion. 2010;50:2167-2175.

53. Lee SH, Du J, Stitham J, et al. Inducing mitophagy in diabetic platelets protects against severe oxidative stress. EMBO Mol Med. 2016;8:779-795.

54. Comfurius P, Bevers EM, Zwaal RFA. Interaction between phosphatidylserine and the isolated cytoskeleton of human blood platelets. Biochim Biophys Acta - Biomembr. 1989;983:212-216.

55. Williamson P, Antia R, Schlegel RA. Maintenance of membrane phospholipid asymmetry, lipid-cytoskeletal interactions or lipid pump? FEBS Lett. 1987;219:316-320.

56. Lhermusier T, Chap H, Payrastre B. Platelet membrane phospholipid asymmetry: from the characterization of a scramblase activity to the identification of an essential protein mutated in Scott syndrome. J Thromb Haemost. 2011;9:1883-1891.

57. Desouza M, Gunning PW, Stehn JR. The actin cytoskeleton as a sensor and mediator of apoptosis. Bioarchitecture. 2012;2:75-87.

58. Leytin V. Apoptosis in the anucleate platelet. Blood Rev. 2012;26:51-63.

59. Stritt S, Beck S, Becker IC, et al. Twinfilin 2a regulates platelet reactivity and turnover in mice. Blood. 2017;130(15):1746-1756.

60. Hoffmann JJML, van den Broek NMA, Curvers J. Reference intervals of reticulated platelets and other platelet parameters and their associations. Arch Pathol Lab Med. 2013;137:1635-1640.

61. Brækkan SK, Mathiesen EB, Njølstad I, Wilsgaard T, Størmer J, Hansen JB. Mean platelet volume is a risk factor for venous thromboembolism: the Tromsø study. J Thromb Haemost. 2010;8:157-162.

62. Thompson CB, Love DG, Quinn PG, Valeri CR. Platelet size does not correlate with platelet age. Blood. 1983;62:487-494.

63. Thattaliyath B, Cykowski M, Jagadeeswaran P. Young thrombocytes initiate the formation of arterial thrombi in zebrafish. Blood. 2005;106:118-124.

64. Blajchman MA, Senyi AF, Hirsh J, Genton E, George JN. Hemostatic function, survival, and membrane glycoprotein changes in young versus old rabbit platelets. J Clin Invest. 1981;68:1289-1294.

65. Handtke S, Steil L, Palankar R, et al. Role of platelet size revisitedfunction and protein composition of large and small platelets. Thromb Haemost. 2019;119:407-420. 
66. Handtke S, Steil L, Greinacher A, Thiele T. Toward the relevance of platelet subpopulations for transfusion medicine. Front Med. 2018;5:1-9.

67. Joutsi-Korhonen L, Sainio S, Riikonen S, Javela K, Teramo K, Kekomäki R. Detection of reticulated platelets: estimating the degree of fluorescence of platelets stained with thiazole orange. Eur J Haematol. 2000;65:66-71.

68. Mezzano D, Hwang K, Catalano P, Aster RH. Evidence that platelet buoyant density, but not size, correlates with platelet age in man. Am J Hematol. 1981;11:61-76.

69. Kono M, Matsuhiroya S, Nakazawa F, Kaido M, Wada A, Tomiyama Y. Morphological and optical properties of human immature platelet-enriched population produced in immunodeficient mice. Platelets. 2018;30:652-657.

70. Wijeyewickrema LC, Lameignere E, Hor L, et al. Polyphosphate is a novel cofactor for regulation of complement by a serpin, $\mathrm{C} 1$ inhibitor. Blood. 2016;128:1766-1776.
71. Subramaniam S, Jurk K, Hobohm L, et al. Distinct contributions of complement factors to platelet activation and fibrin formation in venous thrombus development. Blood. 2017;129:2291-2302.

\section{SUPPORTING INFORMATION}

Additional supporting information may be found online in the Supporting Information section.

How to cite this article: Allan HE, Hayman MA, Marcone S, et al. Proteome and functional decline as platelets age in the circulation. J Thromb Haemost. 2021;19:3095-3112. https:// doi.org/10.1111/jth.15496 